\begin{abstract}
PEERY, ANNETTE IVEY. Caring and Burnout in Registered Nurses: What's the Connection? (Under the direction of Dr. Duane Akroyd.)

In order to prevent burnout among nurses, key causes of burnout must be identified and targeted for direct intervention. The literature discusses burnout among nurses, focusing on burnout due to task-related variables and not patient-related (caring) variables. Two major problems exist with research on burnout and caring in registered nurses (RNs). The first is the lack of robust methods of research utilized to study the concept of caring. The second is the lack of research on the link between caring and burnout in RNs.

The purpose of this study was to examine the relationship between caring and burnout in a sample of RNs in North Carolina. The major hypothesis for this research, was that as RNs report increased levels of caring, they also report higher levels of burnout. Four research questions are addressed in this project.

The population for this study consisted of all RNs within the state of North Carolina. Subjects were selected randomly to obtain a sample of 3,500 to receive a mailed survey. The revised Caring Behaviors Inventory was used to measure the five dimensions of caring (independent variables) and the Maslach Burnout Inventory to measure the three dimensions of burnout (dependent variables). A multiple regression analysis was conducted between each dimension of burnout and four carative factors. This study revealed that the four carative factors identified do impact a nurse's level of burnout and had the greatest impact on the burnout dimension of reduced personal accomplishment. The carative factor of respectful deference for the other contributed the greatest variance in reduced personal accomplishment. Overall, increases in caring led to decreased burnout for this sample.
\end{abstract}


If nurses can be identified as being predisposed to burnout due to their caring attitudes and behaviors, individual and workplace interventions might be developed and implemented to assist in identifying predisposing factors to burnout and, in turn, reduce or prevent burnout in the future. A reduction in burnout may lead to a higher retention rate for nurses, thereby easing the nursing shortage. 


\title{
CARING AND BURNOUT IN REGISTERED NURSES: WHAT'S THE CONNECTION?
}

\author{
By
}

\section{ANNETTE IVEY PEERY}

\author{
A Dissertation \\ Submitted to the Graduate School \\ Of North Carolina State University \\ In Partial Fulfillment of the Requirements \\ For the Degree of Doctor of Education
}

\section{ADULT AND COMMUNITY COLLEGE EDUCATION}

\author{
Raleigh, N.C.
}

2006

Approved by:

Dr. Duane Akroyd

Chair of Advisory Committee
Dr. Conrad Glass

Dr. Kathryn Kolasa

Dr. John Pettitt 


\section{Dedication}

To my husband, Bill,

And

My sons, Roger and Ben,

For their endless supply of love, encouragement, prayers and patience, As well as your many sacrifices during this endeavor.

Also,

To my parents, Billy and Sarah Ivey, For their love, encouragement and support of

My life-long educational endeavors.

I love you all very much! 


\section{Biography}

Sarah Annette Ivey Peery was born July 20, 1961, in Scotland Neck, Halifax County, North Carolina. She received a Bachelor of Science in Nursing from the University of North Carolina at Chapel Hill in May 1983 and a Master of Science in Nursing from East Carolina University, Greenville, North Carolina in May 1996. Annette Peery is also certified as a Diabetes Educator. At the time of this dissertation completion, she is a Clinical Assistant Professor in the School of Nursing at East Carolina University.

Ms. Peery is a member of the nursing honor society, Sigma Theta Tau International and is currently president of the Beta Nu Chapter of this society. She is also a member of Phi Kappa Phi and the National League for Nurses. She was award the Excellence in Education Award from Sigma Theta Tau International Beta Nu Chapter in 2002 and 2004. In 1997 she led the diabetes care path team which was award the Department of Family Medicine Team Recognition Award for the Diabetes Care Path Team at the East Carolina University Department of Family Medicine.

Annette I. Peery resides in Greenville, North Carolina with her husband, Bill, and two sons, Roger and Ben. 


\section{Acknowledgements}

There are many people without whom this dissertation would have never become a reality. I hope that I am not remiss in acknowledging everyone. First, I would like to think Dr. Duane Akroyd, chair of my committee. He remained patient through my “dry spells” and continued to offer advice and encouragement. I would also like to thank my committee members, Dr. Conrad Glass, Dr. John Pettitt and Dr. Kathy Kolasa.

I’d like to say a special "thank you” to Dr. Kolasa. Kathy has served as a mentor for many years and is a very special friend. She strongly supported my decision to begin this educational endeavor and has encouraged me throughout the process.

None of this would have occurred without some tremendous assistance with data entry from nearly 800 surveys - certainly not a feat I could have completed on my own in a timely fashion. Thanks to Dr. Marti Engelke in the East Carolina University School of Nursing Office of Scholarship and Research for assisting me in finding student workers to help enter data. My family went over and beyond the call of duty in this area as well. A big thanks to my aunt, Bobbie Edwards, for the hundreds of surveys she entered and to my mom, Sarah Ivey, for her assistance in helping me track the surveys. Dr. Mel Swanson, also in the ECU SON Office of Scholarship and Research, was a tremendous help in assisting with interpretation of statistical data. And lest, should I never forget that all of the surveys first had to be mailed and labels placed on envelopes! Thank you to Bill, Roger and Ben - my boys - for their hours of sitting in the living room floor doing just that!

A very special thank you to two wonderful mentors - Dr. Ann Schreier and Dr. Nellie Droes - for their "intervention" to help me achieve the final product. Their insight, 
encouragement and brainstorming were priceless! Also, thanks to Dr. Robin Webb-Corbett for unending support and editorial assistance.

Just as important as any of these were those who simply offered prayers and words of encouragement and support, who listened when things were tough, and who shared their stories of their dissertation struggles with me. These were my friends, my family and my coworkers. I hope that I can one day be as much an encouragement to others traveling this road as they have been to me. 


\section{Table Of Contents}

List Of Tables

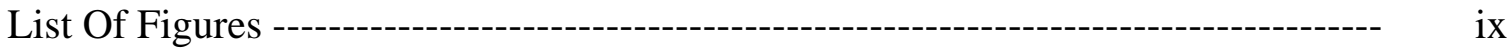

Chapter I: Introduction and Overview ------------------------------------------------------ 1

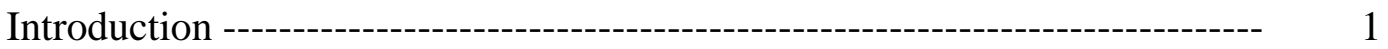

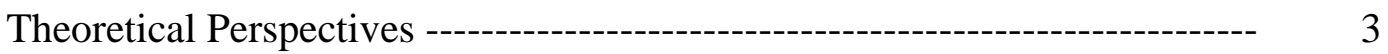

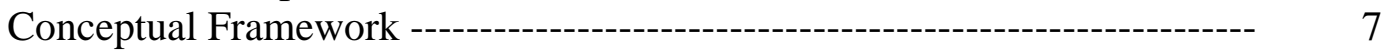

Significance of the Problem----------------------------------------------------- 8

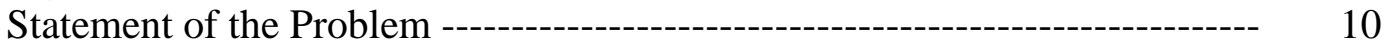

Purpose of the Study ----------------------------------------------------------------- 14

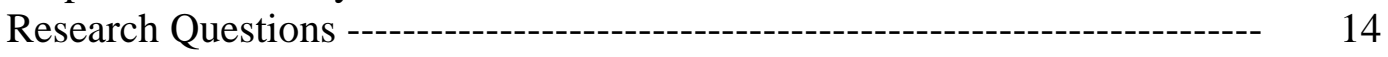

Definition of Terms ------------------------------------------------------------------ 15

Chapter II: Literature Review --------------------------------------------------------------- 17

Literature Review: Caring --------------------------------------------------------- 17

Literature Review: Burnout -------------------------------------------------------- 26

Literature Review: Caring and Burnout ----------------------------------------- 30

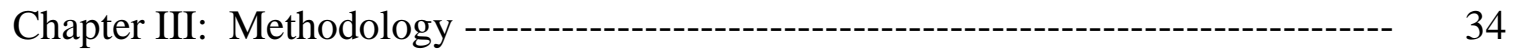

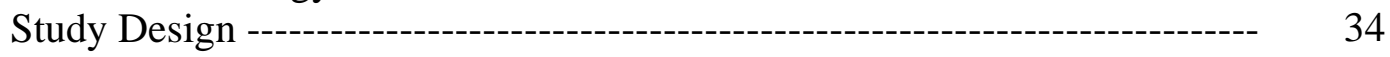

Population and Sample -------------------------------------------------------------- 34

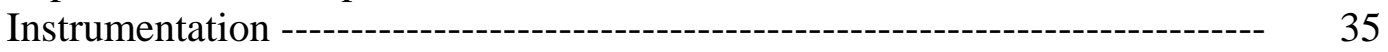

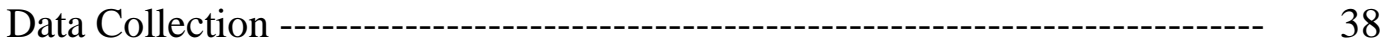

Data Analysis ---------------------------------------------------------------------------- 39

Chapter IV： Results ------------------------------------------------------------------------------ 43

Demographics ---------------------------------------------------------------------------- 43

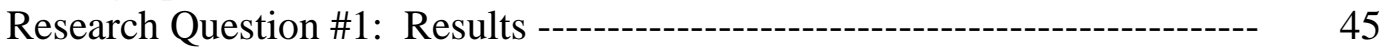

Caring Behaviors Inventory: Factor Analysis ------------------------------------ 48

Research Question \#2: Results -------------------------------------------------- 52

Research Question \#3: Results ---------------------------------------------------- 56

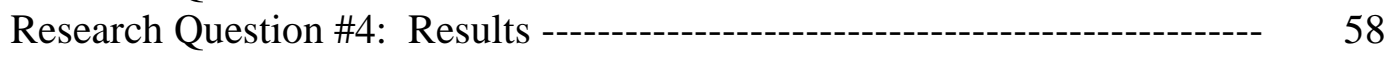

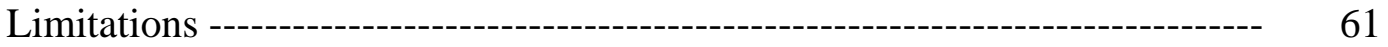

Chapter V: Discussion ------------------------------------------------------------------------- 64

Summary and Conclusions --------------------------------------------------------- 64

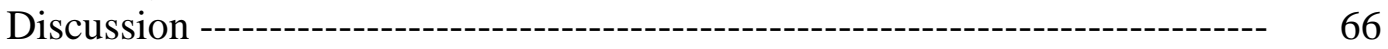

Discussion and Conclusion for Research Question One ------------------------ 67

Discussion and Conclusion for Research Question Two------------------------ 77

Discussion and Conclusion for Research Question Three ---------------------- 79

Discussion and Conclusion for Research Question Four------------------------ 81

Implications for Practice --------------------------------------------------------- 84

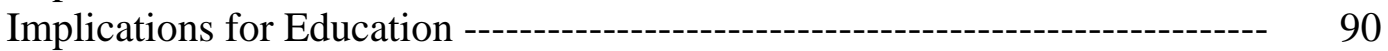


Future Research ----------------------------------------------------------------------- 95

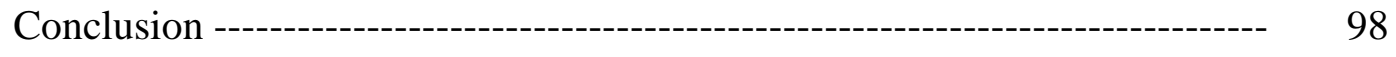

References --------------------------------------------------------------------------------------------- 99

Appendix A: Cover letter and Survey ----------------------------------------------------- 105 


\section{List Of Tables}

Table 1. Five Carative Categories with the Corresponding

Page

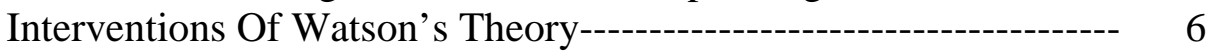

Table 4.1. Demographic Summary of Sample ------------------------------------ 44

Table 4.2. Means and Standard Deviations for MBI Subscales: Study

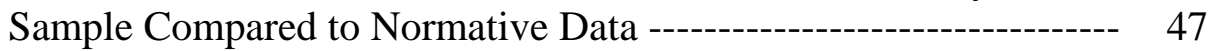

Table 4.3. $\quad$ Factor Loadings for Caring Behaviors Inventory Variables --------- 49

Table 4.4. $\quad$ Bivariate Correlations ----------------------------------------------------- 53

Table 4.5. $\quad$ Regression Analyses Predicting

Emotional Exhaustion Dimension of Burnout ------------------------- 54

Table 4.6. $\quad$ Regression Analyses Predicting

Depersonalization Dimension of Burnout ----------------------------- 57

Table 4.7. $\quad$ Regression Analyses Predicting

Personal Accomplishment Dimension of Burnout -------------------- 60 


\section{List Of Figures}

Chapter I: Introduction

Figure 1. $\quad$ Conceptual Framework ------------------------------------------------------ 8

Chapter IV: Results

Figure 4.1. Scree Plot for Factor Analysis ---------------------------------------------- 50

Figure 4.2. Revised Conceptual Framework ----------------------------------------- 51 


\section{Chapter I \\ Introduction and Overview}

\section{Introduction}

"Caring” is a commonly used word in the English language. Nurses thinking about, doing, and describing nursing, know that caring has unique and particular meanings to them. Caring is one of the first synonyms for nursing offered by nursing students and is surely the most frequent word used by the public in talking about nursing (Boykin and Schoenhofer, 1993). Caring is an essential value in the personal and professional lives of nurses. Understanding the act of caring in its fullest sense, and within both professional and human contexts, is essential.

Nursing is a nurturing profession, and caring is the essential component of its holistic practice. Nursing literature gives emphasis to the value of investigating caring and the way in which it is expressed. Nurses are assumed to develop those psychological characteristics that allow them to provide services in which holistic and individualized care is apparent. Nursing leaders should emphasize the preparation of professionals who are able to care for health and wellness in a manner that contributes to the development of both nurses and patients, and underlines the nature of nursing as a human science (Patistea, 1999).

In today's health care system, the art of caring is often lost to the world of high technology. Nursing education is attempting to create a new paradigm in curriculum development, which will strive to enable nursing graduates to be more responsive to societal needs, more successful in humanizing the highly technological environments of health care, more caring and compassionate, more insightful about ethical and moral issues, more creative, more capable of critical thinking, and better able to bring scholarly 
approaches to patient problems and issues and to advocate ethical positions on behalf of the patients (Bevis and Watson, 2000).

Patients and patient care are stressors. This may include caring for the long-term, chronically ill patient, the aged patient, the dying patient, the patient who makes no progress, the patient who acts in an "unacceptable" manner, and the patient who is unable to communicate. However, stress is very individualized - what is stressful to one individual, may not be to another. In caring for others, nurses give much of themselves. When people care, or give, too much for too long, and receive too little in return, the stress accumulates and burnout occurs (Schaufeli and Enzmann, 1998).

Stress and burnout have been identified as reasons nurses leave the profession (Chung \& Corbett, 1998; Gray-Toft \& Anderson, 1981; Kennedy \& Barloon, 1997; Walsh \& Dolan, 1999). The word "burnout" did not appear in the nursing literature until 1978 in an article by Schubin (McConnell, 1982). Nursing research on stress and burnout has traditionally focused on task-related variables such as workload, caring for the critically and terminally ill, inadequate preparation, lack of staff support, conflict with other nurses, supervisors and physicians (Gray-Toft and Anderson, 1981).

Miller et al. (1988) found that a significant proportion of the burnout experienced by health care workers can be accounted for by empathy variables. Specifically, they found that emotional contagion (sharing or taking-on the emotion of another person), empathic concern (concern for the well-being of another that does not require sharing emotion) and communicative responsiveness (ability to effectively communicate with others about sensitive and emotional topics) contributed significantly to stress and burnout among health care workers (Miller et al., 1988). Omdahl and O’Donnell (1999) 
examined these empathy variables and found that empathetic concern and communicative responsiveness are negatively associated with burnout, while emotional contagion is positively associated with burnout. Their recommendations for interventions focused on nursing education and administration.

\section{Theoretical Perspectives}

Caring and burnout are the two theoretical concepts that guided this research. Before examining the problem addressed in this research, an overview of the theoretical framework is necessary to set the stage. Two conceptual models, or theories, guided this research - Jean Watson’s Theory of Human Caring (1979) and Maslach and Jackson’s Theory of Burnout (1986).

Jean Watson's Theory of Human Caring. When Florence Nightengale published her theory of nursing in 1860, she reflected a caring philosophy in which caring implied a moral imperative in nursing. Since the emergence of modern nursing, care has been at the core of this service. Jean Watson's_Theory of Human Caring emphasizes the moral and ethical dimensions of care. She based her theory of caring and human care on the assumption that health refers to harmony within the mind-body-spirit as a whole being and is expressed by the congruency between the perceived and experienced self (Kim and Kollak, 1999). Watson views nursing as both scientific and artistic, and as a therapeutic interpersonal process. In her theory, caring is considered core to nursing, meaning that caring is intrinsic to the actual nurse-patient process that produces therapeutic results in the person being served (Watson, 1979).

Watson describes human caring as consisting of transpersonal processes designed to help an individual find meaning in illness, suffering, pain, and existence and to help an 
individual gain self-knowledge, self-control, self-care, self-healing, and ultimately, inner harmony (Oermann, 1991). The Theory of Human Caring is based on a value system associated with great respect for life, an acknowledgement of a spiritual dimension to life, and an acknowledgement of the internal power of the human caring process (Oermann, 1991). The theory proposes that individuals engaged in the human caring process must possess a high regard for people and for human life and a high respect for human autonomy and freedom of choice (Oermann, 1991).

Watson (1979) believes that the goal of nursing is to help persons gain a higher degree of harmony within the mind, body, and soul, which generates self-knowledge, self-reverence, self-healing and self-care processes while increasing diversity. This goal may be attained through the implementation of ten carative factors, or interventions. The ten carative interventions are:

- The formation of a humanistic-altruistic system of values.

- The instillation of faith-hope.

- The cultivation of sensitivity to one's self and to others.

- The development of a helping-trusting relationship.

- The promotion and acceptance of the expression of positive and negative feelings.

- The systematic use of the scientific problem-solving method for decision-making.

- The promotion of interpersonal teaching-learning.

- The provision for a supportive, protective and/or corrective mental, physical, sociocultural, and spiritual environment.

- Assistance with the gratification of human needs.

- The allowance for existential-phenomenological-spiritual forces. 
Watson (1979) contends that the carative interventions are interdependent. According to her grouping of the carative interventions based on their interdependency, the ten carative interventions will be combined to produce five carative categories (Table 1). These categories are not progressive and order does not matter. Wolf (1986) and Wolf, Giardino, Osborne and Ambrose (1994) conceptualized the five carative categories in their work.

The first category is that of "assurance of human presence." This category combines the three carative interventions of formation of a humanistic-altruistic system of values, instillation of faith-hope, and cultivation of sensitivity to one's self and to others. The category of "assurance of human presence includes such caring activities as helping the patient, talking with the patient, appreciating the patient as a human being and responding quickly to the patient's call (Brunton \& Beaman, 2000).

The second category is that of "respectful deference." This category combines the two carative interventions of development of a helping-trusting relationship and promotion and acceptance of the expression of positive and negative feelings. The category of "respectful deference" includes caring activities such as being honest with the patient, showing respect for the patient and giving the patient information to make decisions (Brunton \& Beaman, 2000).

The third category is "professional knowledge and skill." This category combines the carative interventions of systematic use of the scientific problem-solving method for decision making and promotion of interpersonal teaching-learning, and includes such caring activities as watching over the patient, being confident with the patient, and paying special attention to the patient on the first visit (Brunton \& Beaman, 2000). The fourth 
category, “positive connectedness,” contains only the carative intervention of provision

for a supportive, protective, and/or corrective mental, physical, sociocultural, and

spiritual environment. This category includes such activities as being hopeful for the

patient, allowing the patient to express feelings and trusting the patient (Brunton \&

Beaman, 2000).

The final category is that of "attentive to other's experience." This category is comprised of the two carative interventions of assistance with the gratification of human needs and allowance for existential-phenomenological forces. Activities included in this category are relieving the patient’s symptoms, putting the patient first and giving good physical care (Brunton \& Beaman, 2000).

Table 1

Five Carative Categories with the Corresponding Carative Interventions of Watson's Theory

\section{Carative Categories}

I. Assurance of Human Presence

II. Respectful Deference

III. Professional Knowledge and Skill

IV. Positive Connectedness

V. Attentive to Other's Experience

\section{Corresponding Carative Interventions of} Watson's Theory

- Formation of humanistic-altruistic system of values

- Instillation of faith-hope

- Cultivation of sensitivity to one' self and to others

- Development of a helping-trusting relationship

- Promotion and acceptance of expression of positive and negative feelings

- Systematic use of scientific problem-solving method for decision making

- Promotion of interpersonal teaching-learning

- Provision for a supportive, protective and/or corrective mental, physical, sociocultural, and spiritual environment

- Assistance with gratification of human needs

- Allowance for existential-phenomenologicalspiritual forces 
Maslach and Jackson's Theory of Burnout. Maslach and Jackson's theory of burnout is the most widely used theory in burnout research (Schaufeli and Enzmann, 1998). Maslach and Jackson describe burnout as a three-dimensional syndrome characterized by emotional exhaustion, depersonalization, and reduced personal accomplishment. They define burnout as a psychological syndrome of these three dimensions that can occur among individuals who work with other people in some capacity (Schaufeli, Maslach and Marek, 1993).

The first dimension is that of emotional exhaustion. In this dimension of burnout, the individual has feelings of being emotionally overextended and depleted of emotional resources. The second dimension, depersonalization, is characterized by negative or excessively detached response to other people, usually the recipients of one's care. The third dimension, reduced personal accomplishment, refers to an individual having a decrease in feelings of competence and successful achievement in work (Schaufeli, Maslach and Marek, 1993). Research by Maslach and Jackson (1982) indicates that an accumulation of a variety of stressors (individual, interpersonal and organizational stress) drives the burnout process.

Caring and burnout are both important and interesting concepts related to nursing that deserve a greater focus in nursing research. Nursing research must ground its research in theory such as this in an effort to prove or disprove theory and/or identify appropriate interventions to prevent and reduce burnout within the profession.

\section{Conceptual Framework}

The conceptual framework for this study is diagrammed in Figure 1. The five carative categories from Watson (1979) and Wolf (1986) are used as independent 
variables, which act on the three dimensions of burnout. The additional independent variables were used as covariates in the model: gender, number of hours worked per week, workload (average number of patients per day), patient acuity level, primary place of work and patient population. These variables were considered as covariates as previous research has indicated that one’s brurnout is impacted by them (Um \& Harrison, 1998; Akroyd \& Adams, 2000; Leiter, Harvie \& Frizzell, 1998; Chung \& Corbett, 1998; Kennedy \& Barloon, 1997; Omdahl \& O’Donnell, 1999; Moffett, 2002).

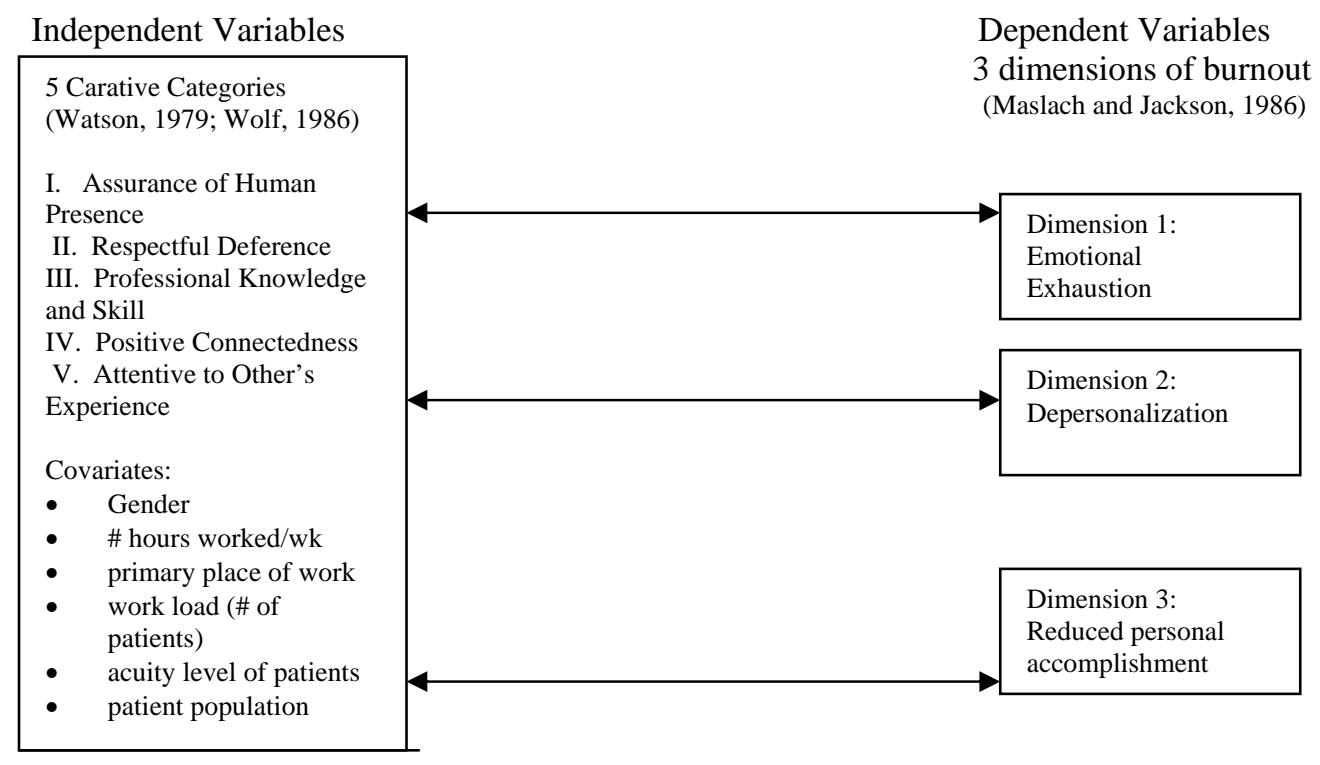

Figure 1: Conceptual Framework

\section{Significance of the Study}

In professional nursing from Nightingale to the present, the concept of caring has been dominant. Traditionally, caring has been projected more as an attitude than an action, although without the action, the attitude becomes mere rhetoric (Barker, 2000). Caring science is an evolving field that is grounded in the discipline of nursing and evolving nursing science, but is rapidly becoming an interdisciplinary or 
transdicsciplinary field of study. It has relevance to all the health, education, and human service fields and professions (Watson, 1999).

As previously mentioned, caring for others is stressful. The literature provides insights into how caring affects, or leads to, increased levels of stress, and how increased levels of stress may lead to increased levels of burnout. A gap exists in the literature in examining how caring directly affects burnout. This study helps to narrow this gap, thereby expanding nursing's body of knowledge.

Previously, the applied nature of burnout research has prompted calls for effective intervention throughout the research literature. This perspective has encouraged considerable effort, but relatively little systematic research. Various intervention strategies have been proposed - some try to treat burnout after it has occurred, whereas others focus on how to prevent burnout. Most discussions of burnout interventions focus primarily on individual-centered solutions, such as removing the worker from the job, or individual strategies for the worker, in which one either strengthens one’s internal resources or changes one's work behaviors. This is particularly paradoxical given that research has found that situational and organizational factors play a bigger role in burnout than individual ones. Individual-oriented approaches may help individuals to alleviate exhaustion, but do not really deal with the other two dimensions of burnout. Also, individual strategies are relatively ineffective in the workplace, where a person has much less control over stressors (Maslach, Schaufeli, \& Leiter, 2001).

If individual nurses can be identified as being predisposed to burnout due to their caring attitudes and behaviors, interventions might be developed and implemented to assist nurses in identifying their predisposing factors to burnout and, in turn, reduce or 
prevent burnout in the future. Additionally, it will be important to note the levels of burnout in various healthcare environments, as organizational interventions might be appropriate in preventing and/or treating high levels of burnout among the nursing staff. This is a very important issue in this time of a nursing shortage and changes in healthcare delivery. However, the literature is extremely limited in research related to interventions to prevent burnout.

\section{Statement of the Problem}

If burnout among nurses is to be prevented, it is critical that key causes of burnout be identified and targeted for direct intervention. The literature discusses burnout among nurses, but has primarily focused on burnout due to task-related variables. Yet some evidence indicates that aspects of caring for others, or client-related variables, are just as predictive or more predictive of burnout (Schaufeli and Enzmann, 1998).

The question arises as to what type of variables are more predictive of burnout task-related variables or client-related (empathy) variables. Schaufeli and Enzmann (1998) compared the results of sixteen studies and found that, overall, common jobrelated stressors such as workload, time pressure, or role conflicts correlate more highly with burnout than client-related stressors such as interaction with difficult clients, problems in interacting with clients, frequency of contact with chronically or terminally ill clients, or confrontation with death and dying. They identified nine studies, including Cordes et al. (1997) and Melchior et al. (1997), in which common job related stressors correlated clearly more highly with burnout than client-related stressors. Three studies (Dames, 1983; Leiter, 1988; Sarros and Friesen, 1987) confirmed the special importance 
of client-related stressors in relation to burnout, specifically contact with terminally ill patients and conflicts in interactions.

Zapf et al. (2001) reported that early research on burnout indicated that common job-related stressors (such as workload, time pressure, or role conflicts) correlated more highly with burnout than client-related stressors (such as problems in interacting with clients, frequency of contact with chronically or terminally ill patients, or confrontation with death and dying). However, the authors discuss the fact that more recent research has focused explicitly on emotion-work variables, such as requirement to display or suppress emotions on the job and the requirement to be emotionally empathic, and has found that these emotion factors do account for additional variance in burnout scores over and above job stressors.

The literature is very weak at best on studies focusing on the caring behaviors and attitudes of nurses and their level of burnout related to it. The one qualitative case study by Kennedy and Barloon (1997) found that high levels of caring, especially with chronically ill pediatric clients, leads to increased levels in stress and burnout, and suggests possible interventions for prevention of burnout in pediatric critical care (Kennedy and Barloon, 1997). Due to the fact that the study is qualitative, the findings are typically not considered to be generalizable. The study also did not take into account previously studied variables related to burnout.

Two over-arching problems exist - methodological concerns and lack of research directly linking caring and burnout. First, the concept of caring is one of the least understood ideas used by professionals (Watson, 1979), and remains a poorly defined concept in nursing practice (Kyle, 1995). Caring is considered an elusive and imprecise 
concept by some (Kyle, 1995). Others (Hegedus, 1999; McCance, McKenna \& Boore, 1997) view caring as an extremely complex concept, with high levels of caring often attributed to higher burnout rates. The etiology of burnout is multifactorial and is determined by complex interactions of occupational and nonoccupational factors and numerous mediators and moderators (Gulielmi and Tatrow, 1998). In studying such a complex concept, descriptive statistics and bivariates may not be complex enough to examine the impact of multiple independent variables on each dimension of burnout. Gulielmi and Tatrow (1998) contend that the etiology of most diseases (including burnout) is multifactorial and is probably determined by a complex interaction of a large number of occupational and nonoccupational factors, a complex interaction of numerous mediators and moderators, and a complex interaction of the two former interactions. Bivariate designs and analytical strategies are not equipped to deal with these entangled relationships (Gulielmi \& Tatrow, 1998).

How much of the variance in burnout could possibly be explained by a nurse's level of caring? Previous studies on burnout and caring (Chung and Corbett, 1998; Kennedy and Barloon, 1997; Omdahl and O’Donnell, 1999; Dyson, 1996; Brunton and Beaman, 2000; Watson, Dreary and Lee, 1999; Dillon and Stines, 1996) have utilized descriptive statistics, ranking of caring attitudes and behaviors, t-tests to measure differences between pre- and post-test, and qualitative methods of research. These types of research methodology are not the best to examine such complex phenomenon. Very few studies (Simmons and Cavanaugh, 2000) have utilized multiple regression to examine caring and its effect on burnout. This study utilized multiple regression. Multiple regression allowed the researcher to determine if a significant relationship exists 
between dimensions of burnout and the five carative categories, if the relationship is statistically significant, and the amount of variance in burnout accounted for by the five carative categories (Hatcher and Stepanski, 1994).

Second, there are a number of studies conducted by nurse researchers, which have focused on caring in nursing practice. These studies have investigated nurses' and patients’ perceptions of effective caring (Kyle, 1995), but very few, if any, which examine the possible predictive value of caring on burnout. Walsh and Dolan (1999), in their study of emergency nurses and their perceptions of caring, concluded that caring may be a casualty of stress and burnout in these nurses, but did not investigate the connection further.

Furthermore, burnout is most often related to quantitative workload instead of qualitative demands resulting from problems in interacting with difficult recipients and dealing with emotional problems of others. Traditionally, emotionally charged interactions with recipients were believed to be the root cause of burnout. However, this assumption is not clearly confirmed by empirical research (Schaufeli and Enzmann, 1998). There is extremely limited empirical evidence on the effect of caring on burnout, especially for nurses. The literature examines the effect of caring on increasing stress (Akroyd and Adams, 2000; Omdahl and O'Donnell, 1999), and on the impact increased stress has on increased burnout (Chung and Corbett, 1998; Um and Harrison, 1998; Gulielmi and Tatrow, 1998), but not on the impact of carative interventions on burnout, holding constant the effect of a variety of task-related variables. 


\section{Purpose of the Study}

The purpose of this study was to examine the relationship between caring and burnout in a sample of registered nurses in North Carolina. The study attempted to narrow or close a gap in the literature by examining the effect of caring on burnout directly, as opposed to the effect of caring on stress and then the effect of stress on burnout.

\section{Research Questions}

1. What are the levels of caring and burnout for registered nurses?

2. What is the predictive value of the five carative categories (assurance of human presence, respectful deference, professional knowledge and skill, positive connectedness, and attentive to other's experience) on the first dimension of burnout (emotional exhaustion), holding constant gender, number of hours worked per week, work load (average number of patients per day), acuity level of patients, primary place of work and patient population?

3. What is the predictive value of the five carative categories (assurance of human presence, respectful deference, professional knowledge and skill, positive connectedness, and attentive to other's experience) on the second dimension of burnout (depersonalization), holding constant gender, number of hours worked per week, work load (average number of patients per day), acuity level of patients, primary place of work and patient population?

4. What is the predictive value of the five carative categories (assurance of human presence, respectful deference, professional knowledge and skill, positive connectedness, and attentive to other's experience) on the third dimension of 
burnout (reduced personal accomplishment), holding constant gender, number of hours worked per week, work load (average number of patients per day), acuity level of patients, primary place of work and patient population?

\section{Definition of Terms}

Burnout: A psychological syndrome of three identified stages (emotional exhaustion, depersonalization, and reduced personal accomplishment) that can occur among individuals who work with other people in some capacity (Schaufeli, Maslach and Marek, 1993).

Caring: Transpersonal processes designed to help a person find meaning in illness, suffering, pain, and existence and to help an individual gain self-knowledge, self-control, self-care, self-healing, and ultimately, inner harmony. Individuals engaged in the human caring process must possess a high regard for people and for human life and a high respect for human autonomy and freedom of choice (Oermann, 1991).

Carative factors: In contrast to curative factors, carative factors are factors that the nurse uses in the delivery of health care to the patient. These factors aim at the caring process that helps the person attain (or maintain) health or die a peaceful death (Watson, 1979). Depersonalization: The second stage of burnout, characterized by negative or excessively detached response to other people, usually the recipients of one’s care. Emotional exhaustion: The first stage of burnout in which the individual has feelings of being emotionally overextended and depleted of their emotional resources.

Reduced personal accomplishment: The third stage of burnout, in which an individual experiences a decrease in their feelings of competence and successful achievement in their work. 
Registered nurse (RN): An individual who has completed a nursing degree from an accredited school of nursing, either associate degree, diploma or baccalaureate degree, and has successfully completed the National Licensure Examination for registered nurses (NCLEX-RN).

Stress: A relationship between an individual and the environment that is appraised by the person as taxing or exceeding his or her resources and endangering his or her well-being (Hobfoll, 1988). 


\section{Chapter II \\ Literature Review}

The purpose of this study was to examine the correlation between the five categories of carative factors and the three dimensions of burnout. The literature review for this study therefore focused on two concepts - caring and burnout, with an emphasis on the concepts as they related to nursing. The first part of this chapter consists of a review of caring literature. The second half of the chapter provides a review of the literature on burnout. Finally, there is a review of the literature that specifically examines the concepts of caring and burnout together.

\section{Literature Review - Caring}

The concept of caring has been nearly exclusively studied within the profession of nursing. Studies on caring tend to focus on caring behaviors as perceived by three main groups - patients, practicing nurses and nursing students. In order to gain a better understanding of the concept of caring, it is important that one review the literature for all three groups. The following literature review is divided into patient perceptions, perceptions of practicing nurses and perceptions of student nurses.

Patient perceptions of caring. Patistea and Siamanta (1999) published a literature review of patients’ perceptions of caring compared with nurses’ perceptions of caring. They reported that there was little in the literature in relation to patient's perceptions of the meanings and processes of caring. Differences between patients and nurses in terms of their perceptions of caring are both rational and expected because every human being is a unique person. These differences show that the provision of individualized care is necessary (Patistea and Siamanta, 1999). 
The literature review presented shows that whereas nurse clinicians focus on the psychosocial aspects of caring, patients assign the highest value to technical skills and professional competence. Similarly to patients, a small proportion of nurses view competent clinical expertise as the fundamental component of caring. Noncaring behaviors included physical and emotional absence, belittling and inhumane actions, and lack of recognition of a patient's uniqueness. Patients' participation in decisions regarding their care may or may not have been an element of a caring interaction. From this literature review, the authors conclude that caring meanings and behaviors are context specific and suggest that nurse clinicians should determine caring needs and actions in the context of practice (Patistea and Siamanta, 1999).

Marini (1999) completed a pilot study to identify which behaviors performed by nursing staff were important indicators of caring as perceived by older adults residing in institutional settings. This study used Watson's Theory of Human Caring as a framework and the Caring Behavior Assessment (CBA) instrument to interview residents. A convenience sample of 21 residents residing in long-term care and assisted-living facilities answered the CBA. The analyses revealed that the highest indicator of nurse caring focused on the nurses' technical competency. The study also noted a significant gender-specific perception of caring, which may reflect differences in gender communication styles and interpersonal processes that affect connotations of caring expressions. Humanistic caring - being treated with respect and as an individual - was the second most important indicator of care. Older adults desired care which preserved and enhanced individual dignity (Marini, 1999). 
From this review of the literature, it appears that patients perceive caring in relation to a nurse's ability to provide safe and competent care. It is extremely important to patients that nurses "know what they are doing” and that they are proficient in the technical aspects of nursing care. Additionally, patients expect nurses to treat them with respect and dignity while providing competent technical care.

Practicing nurses' perceptions of caring. Arthur et al. (1999) surveyed a total of 1,957 registered nurses from 11 countries. The purpose of the study was to compare and contrast the responses of a large international sample of nurses with regard to caring, professional self-concept and technological influences. To collect data, an instrument containing 104 Likert items was administered to registered nurses working in general hospitals. The instrument contained sections which examined professional self-concept, technological influences and caring attributes. Overall, the findings revealed that the nurses sampled in this study believed in creating a sense of trust and developing a confident relationship between nurses and patients based on truth and respect. The relationship should allow the patient to express feelings and the nurse should listen to and pay attention to the patient. The sample expressed the importance of feeling concern, not avoiding and the importance of involving the patient in their care. In terms of caring attributes, all respondents scored greater than 3, the arbitrary mid-point of the caring continuum. The total samples’ view of technology revealed an agreement with the need for "high tech" skills and that in general, high technology enhances patient care and wellbeing. The findings indicate that nurses world wide do share much in common while still retaining individual cultural features related to caring and their practice as nurses (Arthur et al., 1999). 
Dyson (1996) completed a pilot study in which she investigated nurses’ conceptualizations of caring. A sample of nine qualified nurses was used and Kelly’s repertory grid technique employed to elicit constructs within the concepts of caring attitudes and caring behaviors. After grid data were analyzed, nine common themes were identified. These nine themes were: consideration and sensitivity, giving of self, work style, motivation, communication and meeting needs, knowledge and learning, individual approach, general approach, and honesty and sincerity. The findings of this study largely supported the concept that caring is a combination of what the nurse does and what the nurse is like as a person. The results from this study highlighted some of the key elements in nurses’ conceptualizations of care. These largely supported the findings of previous studies, with the emphasis on the humanistic and psychosocial components of care (Dyson, 1996).

Hegedus (1999) examined providers’ and consumers’ perspectives of nurses’ caring behaviors. The purpose of her study was to develop and test a scale designed to examine nurses’ caring behaviors. She reported on a pilot study conducted with a convenience sample of 42 nurses (providers) and 39 patients (consumers) in two community hospitals in the New England Region. The Wilcoxon two-sample rank-sum test was used to test the difference in rank of the 20 items between the providers and the consumers. There was a significant difference between the providers and the consumers in the ranking of nine of the 20 items. The consumers valued behaviors that recognized their individual perspective as well as that of their family and behaviors that helped them anticipate and prepare for change. The providers placed a greater emphasis on the behaviors that were more geared towards the comforting aspects of care by encouraging 
patients to express and vent their feelings. The findings of this study might allow clinicians to be sensitized to their caring behaviors by increasing their realization of how behaviors are perceived by patients. The author concluded that the instrument being developed needed minor revisions and further testing (Hegedus, 1999).

Brunton and Beaman (2000) explored nurse practitioners’ perceptions of their own caring behaviors, the relationship between sociodemographic variables, environmental factors, and nurse practitioner's perceptions of their caring behaviors. Perceptions of 40 caring behaviors were measured using a revised Caring Behaviors Inventory (CBI). The inventory assessed five dimensions of caring: courteous regard, investment in other's needs, readiness to help, knowledge and skill, and appreciation of other's perspective. Additionally, several sociodemographic and professional characteristics were assessed. Surveys were mailed to 200 members of an Illinois nurse practitioner group, with a return rate of 140 surveys. After the data was analyzed, the top ten caring behaviors, in rank order, were appreciating the patient as a human being, showing respect for the patient, being sensitive to the patient, talking with the patient, treating patient information confidentially, treating the patient as an individual, encouraging the patient to call with problems, being honest with the patient, and listening attentively to the patient. The authors conclude that caring is nurses' hidden work that may go unrecognized, except when the caring behaviors are missed by the patients or their families (Brunton and Beaman, 1999).

While patients indicate that technical expertise is a key concept of caring, nurses do not share that perception. Perhaps this is because nurses assume that their profession and job mandate technical expertise - it is an expectation, not a choice. Nurses do 
perceive caring as an issue of choice. Hopefully, nurses choose to promote trust and respect in relationships with patients and families, provide individualized care and collaborate with the patients regarding decisions pertinent to their health care.

Student nurses' perceptions of caring. Simonson (1996) reports on phenomenological research designed to discover how caring was taught in an associate degree nursing education program. Three basic questions were: 1) What is the meaning of caring to the faculty and students, 2) How do the faculty communicate this meaning to the students; and 3) How does this meaning shape the experience of the students? Data were collected using semi-structured interviews with all faculty and selected students, classroom observations, and a review of documents. Data was analyzed for and found to have content explaining the meaning of caring, how caring is being taught and what students are learning about caring. Four carative factors (from Watson's Theory of Human Caring) emerged as descriptions for the major themes and helped explain how caring and caring values were communicated in the nursing program. The meaning of caring as essential to what nursing is and what nurses do came across in the words and behaviors of faculty and students. Faculty practiced values congruent with caring and were able to actualize these values in the classroom - a major means of communicating them to students. Implications derived from this study speak to the need for faculty to have caring or a way of being if they wish to communicate caring as the essence of nursing to students (Simonson, 1996).

Kosowski (1995) describes a phenomenological study in which the purpose was to discover, describe and analyze how nursing students learn professional nurse caring in the clinical context of nursing education. Data was collected via interviews with 18 
female baccalaureate nursing students. The participants narrated their stories about learning caring by first describing their understanding of how they created caring with patients. After discussing their patient care interactions, they were then able to answer the research question of how they learned caring in clinical. From the data analysis, two constitutive patterns were identified - creative caring (containing seven themes) and learned caring (containing five themes). The students became aware that they simultaneously created and learned caring and personified it into a way of acting, thinking, and feeling about the patient care experience that characterized caring for them (Kosowski, 1995).

Dillon and Stines (1996) state that caring is an essential component in nursing that must be affirmed and nurtured. They completed a phenomenological study of facultystudent caring interactions by exploring the perceptions of faculty caring behaviors as experienced by students at the practical nurse and nurses' aide levels. Their study replicated a previous phenomenological study of baccalaureate nursing students. The results indicated that the participants perceived caring as recognition of their unique individuality and the sharing and giving of self and time by the faculty. The authors of this study believe that the knowledge acquired in this study could be utilized by nursing faculty in order to reinforce or enrich caring interactions with students (Dillon and Stines, 1996).

The purpose of a study published by Hanson and Smith (1996) was to describe the meaning of baccalaureate nursing students' lived experience of caring and not-so-caring interactions with faculty. Seventeen baccalaureate nursing students at a private liberal arts college and 15 baccalaureate nursing students at a public university were 
interviewed. Transcripts were analyzed using Giorgi’s technique. Significant statements were identified, meaning units were developed, and themes were extracted and abstracted into the categories of recognition, connection, and confirmation/affirmation. General structural descriptions of the phenomena of a caring and not-so-caring interaction were constructed. The results have implications for nurse educators. Providing a caring environment not only serves a humanistic purpose of enhancing students' positive feelings and self-esteem, but also relates to increasing motivation to study and learn and affirming students’ choice of nursing as a profession (Hanson and Smith, 1996).

Watson, Deary and Lea (1999) completed a longitudinal study with nursing students to determine if their perceptions of caring changed over time, throughout nursing school. Another purpose of their study was to determine if the Caring Dimensions Inventory (CDI) instrument could detect any changes in the students' perceptions of caring. The CDI was developed in 1997 and consists of 25 operationalized statements of nursing actions. Subjects are asked to indicate their agreement that each statement constitutes caring by using a 5 -point Likert scale ( $1=$ strongly disagree to $5=$ strongly agree). The instrument focuses on two dimensions of caring - the "psychosocial" (emotional) and the "professional and technical" (physical). The psychosocial dimension includes listening to the patient and sitting with the patient. The professional and technical dimension includes taking vital signs and reporting on a patient's condition.

The sample consisted of student nurses in Scotland between 1994 and 1996. There were 168 participants the first time the questionnaire was given, 124 at 12 months and 90 at 24 months. The sample was representative of Scotland's population of nurses and nursing students. The students' perceptions of caring related to the professional and 
technical aspects of caring increased over the time of the study. However, a similar increase was not found in the other dimensions of caring (psychosocial, inappropriate aspects of nursing, being cheerful with a patient). Th authors suggested that further research be done with nurses in clinical practice to see if increases occur in these areas after individuals complete their undergraduate nursing education and become less "task oriented” (Watson, Deary, and Lea, 1999).

Simmons and Cavanaugh (2000) reported on a longitudinal study of the development of caring ability in registered nurses. A nationwide sample of female graduates of United States baccalaureate nursing programs was resurveyed three years after the survey was taken during nursing school. The purpose of this study was to evaluate variables contributing to the development of professional caring ability. Caring ability was measured using the Caring Ability Inventory, maternal and paternal care was measured using the Parental Bonding Instrument and the caring climate of the nursing schools was assessed using the School climate Profile. Caring ability scores significantly increased after entry into practice (paired student's t-test, $\mathrm{P}<.001$ ). The strongest predictor of postgraduate caring ability was the student's caring ability scores ( $r=.58$, $\mathrm{P}<.001$ ). When student caring ability scores were excluded as a potential predictor, school climate scores were the strongest predictor of postgraduate caring ability $(r=.17$, $\mathrm{P}<.05$ ). This suggests that development of professional caring ability is related to caring school environments. Additionally, caring ability as a student predicts further development of caring ability after entry into practice (Simmons and Cavanaugh, 2000). 
The literature related to students' perceptions of caring tend not to look at specific caring characteristics, but instead how caring is conveyed within faculty-student interactions and the nursing school environment. Overall, the research indicates that a student's perception of caring is greatly influenced by the caring they have experienced with faculty and within their nursing school.

One’s perception and level of caring - whether positive or negative - may be a source of increased stress. Throughout the literature, it has been documented that increased levels of stress, particularly when coupled with highly technical work environments, may lead to burnout. Therefore, this study will look at the concepts of both caring and burnout.

\section{Literature Review - Burnout}

The concept of burnout has been studied within many professions and occupations. While a great deal of literature on burnout exists, this literature review focused on burnout within human services occupations. The first part of this literature review focuses on burnout in general, while the last part discusses literature that speaks to burnout in nursing.

Um and Harrison (1998) developed and empirically evaluated a causal model that delineated the processes whereby clinical social workers experience burnout and job dissatisfaction in their workplaces. Specifically, they examined role stressors, burnout, individual coping skills, social support, and level of workers’ job dissatisfaction within a multivariate context for the purpose of making causal inferences using linear structural relation model (LISREL). 
First, their proposed model specified interrelationships among work stressors and burnout, the intervening factors between burnout and job satisfaction, and the final outcome variable, job satisfaction. Then, the theoretical model was translated into an empirically testable model. Finally, the model was tested with a sample of 165 clinical social workers in Florida. The results of analysis of components fit indicated that role conflict did intensify the amount of burnout and job dissatisfaction. Social support acted as an intervening and moderating factor between burnout and job dissatisfaction (Um and Harrison, 1998).

Gulielme and Tatrow (1998) provided a review of the literature on the effect of occupational stress and burnout on health in teachers. Their review brings to light many of the problems associated with methodological and conceptual considerations in previous studies done on the concepts of burnout, occupational stress, and health. In general, the literature supported the view that occupational stress and burnout are associated with poor health in teachers (Gulielmi \& Tatrow, 1998). This view held true regardless of the measures used and the subject population (regular, special education, or college teachers). However, the authors caution that the methodological rigor and sophistication of the studies could be more sound, as these studies have relied exclusively on self-report intervention and on more descriptive than correctional analyses (Gulielmi \& Tatrow, 1998).

Akroyd and Adams (2000) examined burnout in a sample of radiation therapists, using Maslach and Jackson's theory of burnout as the conceptual model. They examined the magnitude of burnout at each of the three stages on burnout, compared the burnout levels of radiation therapists to other professional groups and whether or not there was a 
relationship between the number of patients treated per week and the levels at each stage of burnout. The authors sampled 1,200 radiation therapists (603 returned), and collected data using the Maslach Burnout Inventory (MBI). The study results indicated that the therapists had high levels of emotional exhaustion and depersonalization and relatively low to moderate levels of personal accomplishment. Additionally, radiation therapists had significantly greater levels of emotional exhaustion and depersonalization than mental health workers and medical workers. The therapists also had a significantly lower level of personal accomplishment than mental health workers and medical workers. Therapists indicated significantly lower levels of burnout related to personal accomplishment than did nurses. Finally, as the number of patients treated each week increased, the levels of burnout increased, with the greatest increase in emotional exhaustion and depersonalization (Akroyd \& Adams, 2000). Potential interventions were also briefly discussed.

Leiter, Harvie, and Frizzell (1998) examined the relationships of nurse burnout, intention to quit, and meaningfulness of work as assessed on a staff survey with patient satisfaction with nursing care, physician care, information provided and coordination of care, and outcomes of the hospital stay assessed post-discharge. The purpose of the study was to explore the correspondence of nursing staff burnout and patient satisfaction with care. Sixteen inpatient units from two hospitals sites compiled the data base and included 605 patients and 711 nurses. Patients' perceptions of the quality of each of four care dimensions corresponded to the relationships nurses had with their work. Patients on units where nurses found their work meaningful were more satisfied with all aspects of their hospital stay. Patients who stayed on units where nursing staff felt more exhausted 
or more frequently expressed the intention to quit were less satisfied with the various components of their care. No significant correlations were found between nurse professional efficacy and any of the patient satisfaction components measured (Leiter, Harvie, and Frizzell, 1998).

Chung and Corbett (1998) conducted a pilot study to compare the burnout of nursing staff who worked with clients who displayed challenging behavior in hospitalbased bungalows and a community unit in the United Kingdom. Twenty-six and twelve nursing staff were randomly chosen form four hospital-based bungalows and a community unit. Staff assessed their clients’ behavior using the Aberrant Behavior Checklist and were later interviewed, using a self-constructed Staff Questionnaire and the Maslach Burnout Inventory. The results showed that clients in the hospital-based bungalows were more severe in challenging behavior than those in the community unit. The staff in the hospital-based bungalows were less satisfied with their salaries and enjoyed their client contact less. They complained more than the community unit staff and felt that their present training was inadequate. They were also more emotionally exhausted and experienced more depersonalization towards clients than the community unit staff. The level of personal accomplishment was, however, similar in the two groups. Correlations showed that there were significant associations between staff burnout and management issues rather than clients' behavior, particularly in the hospitalbased bungalow group (Chung and Corbett, 1998).

Burnout affects the retention rate of nurses throughout the country and within all healthcare agencies. Due to numerous factors, including inadequate staffing, critically ill patients, high patient loads and lack of support from administration, nurses begin in a job 
they love only to develop exhaustion, cynicism and an inability to provide adequate care to their patients. Ask a nurse how they feel when they leave their job for the day. Unfortunately, common answers might include "I feel frustrated that I could not provide what I feel is adequate care for my patients;" "I feel exhausted and too tired to go home to take care of my family and myself;" or "I feel powerless in the agency and no one listens to what we, as staff nurses, have to say.” Burnout is not unique to nursing, but often seems to occur earlier in the careers of nurses - often within the first four years of practice.

\section{Literature Review - Caring and Burnout}

A review of the literature in education, health care in general, and nursing was extremely limited in research which examined the relationship(s) directly between caring and burnout. Of the three studies located, one was qualitative and the other two were quantitative studies, one using multiple regression analysis.

Kennedy and Barloon (1997) focused on pediatric critical care nurses, especially those who care for chronically ill children, since they are at high risk for burnout. The article reviewed the dynamics of chronicity in pediatric critical care and explored protective strategies for burnout management. These strategies require attention to the feelings of the nurses' and the ethical decisions of patient care, in which they are involved. The strategies suggested by the authors included peer support groups, an environment supportive of the mental, physical, social and spiritual needs of nurses, and breaks from working in pediatric intensive care units. These strategies are particularly important when caring for patients with prolonged, chronic suffering. The rewarding aspects of caring for the critically ill child who recovers are not experienced when caring 
for the child with a chronic illness, as they often do not recover (Kennedy and Barloon, 1997).

Omdahl and O’Donnell (1999) collected data from registered nurses at two hospitals to examine the extent to which empathy variables contributed to nursing stress and occupational commitment. The empathy variables examined were emotional contagion (sharing the emotions of patients), empathic concern (being concerned for patients) and communicative effectiveness (effectively communicating with patients and their families). Nursing stress and burnout were explored through variables of emotional exhaustion, depersonalization, and reduced personal accomplishment. Multiple regression analyses revealed that the combination of the three emotional communication variables explained significant proportions of the variance in all three of the stress variables, as well as occupations commitment. The analyses further revealed that a lack of empathic concern and poor communicative responsiveness and high emotional contagion significantly contributed to reduced personal accomplishment. Emotional contagion explained a significant proportion of the variance in emotional exhaustion. Emotional contagion also significantly reduced occupational commitment (Omdahl and O’Donnell, 1999).

Moffett (2002) completed a study to explore the relationship between the affective component of caring and burnout in nursing. A descriptive, cross-sectional correlational design was used to collect data concerning caring attitudes, components of burnout, and perception of workload. The sample consisted of 350 staff nurses employed full-time in Louisiana. They were asked to complete an instrument designed to measure caring (The Caring Inventory: Nurse Form [CI-N]), burnout (MBI), and perception of 
workload. The researcher found a significant negative correlation between scores on the CI-N and the emotional exhaustion and depersonalization sub-scales of the MBI. Using linear regression, caring accounted for $17 \%$ of the variance in scores on emotional exhaustion and $7 \%$ of the variance in scores on personal accomplishment. Perceptions of changes in workload over the last two years was significantly correlated with the depersonalization and emotional exhaustion sub-scales of the MBI. No relationship was found between caring and the perception of workload. This study concluded that caring attitudes can serve as a mediator of burnout in nurses and enhance the feeling of personal accomplishment (Moffett, 2002).

As previously mentioned, research is limited on the concepts of caring and burnout alone. It is well documented in the literature that increased levels of stress, which may be due, in part, by higher levels of caring and empathy, leads to increased incidence of burnout. Research should begin to focus on the factors that lead to increased stress and how these factors, independently, impact burnout. This study proposes to do this by looking at the impact of caring on burnout.

The literature on caring and burnout provides an overview of the two concepts, but none of the reviews provided studies as the one proposed here. Based upon the literature review, this study identified the problem discussed in Chapter I. This study examined the correlation between the five carative categories and the three dimensions of burnout. The plan to examine these concepts is explained in the following chapter.

If burnout among nurses is to be prevented, it is critical that key causes of burnout be identified and targeted for direct intervention. The literature discusses burnout among nurses, but has primarily focused on burnout due to task-related variables. Yet some 
evidence indicates that aspects of caring for others, or client-related variables, are just as predictive or more predictive of burnout (Schaufeli and Enzmann, 1998). 


\section{Chapter III \\ Methodology}

\section{Study Design}

The purpose of this study was to examine the relationship between caring and burnout in a sample of registered nurses in North Carolina. The study attempts to close a gap in the literature by examining the effect of caring on burnout directly, as opposed to the effect of caring on stress and then the effect of stress on burnout. A correlational design was used in this study to examine the aforementioned relationships.

The purpose of the correlational design was to generalize from a sample to a population so that inferences can be made about the relationship(s) between caring and burnout (Creswell, 1994). A correlational design using a survey to collect data was preferred for this study due to the ease of distributing the survey and collecting data from the population throughout North Carolina. A mailed survey was the most feasible and economical method to utilize in obtaining these data from a diverse sample of the population. The survey was cross-sectional.

\section{Population and Sample}

The population for this study consisted of all registered nurses (RNs) within the state of North Carolina. As of March 2000, the RN national survey completed by the U.S. Department of Health and Human Services, Bureau of Health Professions, Division of Nursing, estimated that there were 2,696,540 registered nurses in the United States. In North Carolina, there were 92,307 currently licensed registered nurses, with 69,253 being currently employed in nursing. 
The sample for this project was randomly chosen from a listing of all registered nurses, currently employed in nursing, in North Carolina. The sampling design for this population was single stage. Subjects were selected randomly via use of a random number table to ensure a systematic sample. The use of a random sample allows the research findings to be more generalizable to the population as this design is more rigorous. Tabachnick and Fidell (1989) suggest that if multiple regression is used, one would like to have 20 times more cases than independent variables, but preferable no fewer than 100 cases as this may make the power unacceptably low. As this study had eleven independent variables, a sample size of at least 220 was preferred. Therefore, surveys were mailed to 3,500 RNs in North Carolina in hopes of obtaining a sample size of at least 1,000 RNs. The criteria for the sample population included that they were: 1) currently licensed to practice as a registered nurse in North Carolina, and 2) were currently employed full-time as a registered nurse in North Carolina.

\section{Instrumentation}

One survey, combining three instruments, was used for this study. Demographic information questions were also added for a final single survey to be mailed. The instrument consisted of three sections.

Maslach Burnout Inventory. The first section was the Maslach Burnout Inventory

- Human Services Survey (MBI-HSS) (Maslach and Jackson, 1996). It measures burnout as it manifests itself in staff members in human services institutions and health care occupations such as nursing, social work, psychology, and ministry. The MBI-HSS consists of 22 items that measure burnout in terms of emotional exhaustion (nine items), depersonalization (five items), and personal accomplishment (eight items). The 
frequency with which the respondent experiences each item is measured on a seven-point Likert-type scale anchored by Never (0) and Every Day (6). The scores thus can range from $0-54$ on the emotional exhaustion subscale, $0-30$ on the depersonalization subscale, and $0-48$ on the personal accomplishment subscale. Because burnout is conceptualized as three separate dimensions, three scores are used for each factor (emotional exhaustion, depersonalization, personal accomplishment). Higher mean scores on the emotional exhaustion and depersonalization subscales correspond to higher levels of burnout, whereas lower mean scores on the personal accomplishment subscale correspond to higher levels of burnout (Maslach and Jackson, 1986). Levels of emotional exhaustion were categorized within ranges of 0-16 (low), 17-26 (moderate), and 27 or over (high), whereas levels of depersonalization ranged from 0-6 (low), 7-12 (moderate), and 13 or over (high).

MBI: Reliability. Internal consistency was estimated using Cronbach's coefficient alpha and reported reliability coefficients of .90 and .79 for the emotional exhaustion and depersonalization subscales, respectively, and 0.71 for personal accomplishment (Maslach, Jackson \& Leiter, 1996). Test-retest reliability coefficients for the emotional exhaustion and depersonalization subscales were .82 and .60 , respectively.

MBI: Validity. Convergent validity studies indicate that the MBI-HSS/ES scales measure the same construct as other burnout instruments. Correlations of emotional exhaustion and depersonalization with other burnout self-report indicators are high (rs > .50 ), whereas correlations with personal accomplishment are somewhat lower (rs $=.30$ ). Generally, MBI-scores are moderately related to information from external sources such as peer-ratings (rs = .30) (Schaufeli and Enzmann, 1998). 
Caring Behaviors Inventory. The second section of the survey was comprised of the Caring Behaviors Inventory (CBI), which measures nurses, and/or patients, perceptions of nurses caring attitudes and actions, and separates these into the five carative categories. Wolf (1986) devised the CBI by selecting from the literature, words, or phrases that represented caring. The CBI includes 43 items, with a 4-point Likert-type scale used to elicit responses ( 1 = strongly disagree; 2 = disagree; 3 = agree; 4 = strongly agree) to each of the caring words or phrases (Kyle, 1995; Wolf et al., 1994).

The CBI results in five carative categories, which fit with Watson's Transpersonal Caring Theory (Kyle, 1995; Wolf et al., 1994). The five carative categories of the CBI include: assurance of human presence (12 items); respectful deference to the other (12 items); professional knowledge and skill (5 items); positive connectedness (9 items); and attentiveness to the other's experience (4 items) (Wolf et al., 1994).

CBI: Reliability. Cronbach's alpha coefficients for the five categories and/or overall instrument scores have been reported by other researchers using the CBI (Coogan, 1996; Swan, 1998; Urden, 1996). All coefficients were high, ranging from .93 to .99. Test-retest reliability was established $(\mathrm{r}=.96, \mathrm{p} \leq .0001$; rho $=.88, \mathrm{p} \leq .0001)$ on a nurse sample. The alpha coefficient was .83 .

CBI: Validity. Content validity was established by a panel of four nurse experts. Construct validity of the contrasted groups type was established comparing nursing staff ( $n=278)$ and patient $(n=263)$ responses on the total scores of both groups. An unpaired $\mathrm{t}$-test revealed that the groups were different $(\mathrm{t}=3.01 ; \mathrm{df}=539 ; \mathrm{p}=.003)$. As this instrument may be used to survey different samples, i.e. nurses and patients, there is a concern regarding the differences in construct validity between the different sample 
types. While evidence of content validity is the weakest type of evidence, and given the limited evidence of construct validity in this study, an exploratory factor analysis will be performed on the data. A factor analysis of the CBI was not reported in the literature to delineate the factor structure of the theory for the CBI used with nurses only and information was not provided on construct validity of the instrument (previous factor analysis was completed using combined nurse and patient responses (Wolf et al., 1994), which are not consistent).

Demographic Data. The third section of the survey consisted of demographic data. This part included age, gender, type of employment within nursing (full-time or part-time), number of hours worked per week, average number of patients cared for per week, site of primary nursing employment, patient population and level of patient acuity. Refer to Appendix A for the actual cover letter and survey.

\section{Data Collection}

A cover letter signed by the researcher, accompanied by the survey and a preaddressed, postage-paid return envelope was mailed to 3,500 registered nurses selected for the sample. All surveys were coded so non-respondents could be identified for subsequent mailings; however, anonymity of respondents was maintained for other purposes. A follow-up letter and new survey were mailed to non-respondents after six weeks. Required paperwork for this research was submitted to the Institutional Review Board, Human Subjects Committee of North Carolina State University prior to beginning the process of data collection. 


\section{Data Analysis}

Data collected from returned surveys were entered into a computer database by the researcher. This database file was then processed using SAS Version 8 (SAS Institute, 1999-2001) for analysis. The following procedures were utilized for each research question.

Research Question \#1: What are the levels of caring and burnout for registered nurses?

Data regarding the three dimensions of burnout and the five carative categories were analyzed. Univariate statistics on the three dimensions of burnout and the five categories of carative factors were examined to determine the levels of caring and burnout for the sample of registered nurses. Burnout means for the sample were compared with National Norms for each dimension of burnout.

Research Question \#2: What is the predictive value of the five carative categories (assurance of human presence, respectful deference, professional knowledge and skill, positive connectedness, and attentive to other's experience) on the first dimension of burnout (emotional exhaustion), holding constant gender, number of hours worked per week, work load (average number of patients per day), acuity level of patients, primary place of work and patient population?

First bivariate correlations were examined between emotional exhaustion (dependent variable) and all five caring categories (independent variables). Only those independent variables with significant bivariate relationships were included in the regression model. This technique is suggested by Hatcher and Stepanski (1999) for model building for multiple regression. Finally, a multiple regression was run with only 
those independent variables that were significantly correlated with the dependent variables. Covariates (gender, number of hours worked per week, work load (average number of patients per day), acuity level of patients, primary place of work and patient population) were added to hold their effect constant. Multiple regression analysis was chosen because this study used a single continuous dependent variable and two or more independent variables measured on an interval/ratio scale. Multiple regression allowed the researcher to 1) determine if linear combination of variables significantly effects variance in the independent variable; 2) determine which independent variable significantly $(\mathrm{p} \leq .05)$ contributed to variance in the dependent variable, while holding constant the covariates (gender, number of hours worked per week, work load, acuity level of patients, primary place of work and patient population); and 3) determine the magnitude of the effect of significant predictors (Hatcher and Stepanski, 1999).

Research Question \#3: What is the predictive value of the five carative categories (assurance of human presence, respectful deference, professional knowledge and skill, positive connectedness, and attentive to other's experience) on the second dimension of burnout (depersonalization), holding constant gender, number of hours worked per week, work load (average number of patients per day), acuity level of patients, primary place of work and patient population?

First bivariate correlations were examined between depersonalization (dependent variable) and all five carative categories (independent variables). Only those independent variables with significant bivariate relationships were included in the regression model. This technique is suggested by Hatcher and Stepanski (1999) for model building for multiple regression. Finally, a multiple regression was run with the five carative 
categories comprising the independent variables and depersonalization as the dependent variable. Covariates (gender, number of hours worked per week, work load (average number of patients per day), acuity level of patients, primary place of work and patient population) were added to hold their effect constant. Multiple regression analysis was chosen because this study uses a single continuous dependent variable and two or more independent variables measured on an interval/ratio scale. Multiple regression allowed the researcher to 1) determine if linear combination of variables significantly effects variance in the independent variable; 2) determine which independent variable significantly $(\mathrm{p} \leq .05)$ contributes to variance in the dependent variable, while holding constant the covariates (gender, number of hours worked per week, work load, acuity level of patients, primary place of work and patient population); and 3) determine the magnitude of the effect of significant predictors ( Hatcher and Stepanski, 1999).

Research Question \#4: What is the predictive value of the five carative categories (assurance of human presence, respectful deference, professional knowledge and skill, positive connectedness, and attentive to other's experience) on the third dimension of burnout (reduced personal accomplishment), holding constant gender, number of hours worked per week, work load (average number of patients per day), acuity level of patients, primary place of work and patient population?

First bivariate correlations were examined between reduced personal accomplishment (dependent variable) and all five carative categories (independent variables). Only those independent variables with significant bivariate relationships were included in the regression model. This technique was suggested by Hatcher and Stepanski (1999) for model building for multiple regression. Finally, a multiple regression was run 
with the five carative categories comprising the independent variables and reduced personal accomplishment as the dependent variable. Multiple regression analysis was chosen because this study uses a single continuous dependent variable and two or more independent variables measured on an interval/ratio scale. Multiple regression allowed the researcher to 1 ) determine if linear combination of variables significantly effects variance in the independent variable; 2) determine which independent variable significantly $(\mathrm{p} \leq .05)$ contributes to variance in the dependent variable, while holding constant the covariates (gender, number of hours worked per week, work load, acuity level of patients, primary place of work and patient population); and 3) determine the magnitude of the effect of significant predictors ( Hatcher and Stepanski, 1999). 


\section{Chapter IV \\ Results}

\section{Demographics}

Of the approximately 70,000 registered nurses (RNs) working full time in North Carolina, 3,500 (5\% of the population) were surveyed. The initial survey mailing for this study consisted of 3,500 survey questionnaires mailed to a random sample of these RNs. Of these 3,500 questionnaires, 818 (23.4\%) were returned. There were 2,682 nonrespondents on the first mailing. A second mailing was sent to a random sample of 350 individuals from the initial group of 2,682 nonrespondents. The number of questionnaires returned was 70 (20\%). The final rate of return for all questionnaires (first and second mailing combined) was 888 (25.4\%). The variables studied in this project were the three dimensions of burnout - emotional exhaustion, depersonalization and personal accomplishment; five carative factors - assurance of human presence, respectful deference to the other, professional knowledge and skill, positive connectedness and attentiveness to the others experience; and demographic data including age, gender, number of hours worked per week, average number of patients cared for per week, site of primary nursing employment and level of patient acuity.

In March 2000, the U.S. Department of Health and Human Services reported that there were 2.7 million registered nurses in the United States and its territories (USDHHS, 2002). As of December 2004, North Carolina reported 76,308 registered nurses currently employed in nursing. The sample for this study is representative of the state (North Carolina) and national population of registered nurses employed in nursing. As is expected in the profession of nursing, the sample for this study was $94.63 \%$ female, compared to a national rate of $94.6 \%$ and a state rate of $93 \%$. With respect to age, the 
sample was reasonably close to the national percentages. Nationally, 31.7\% of nurses are

between the ages of less than 25 years to 39 years, 34.4\% between the ages of 40 and 49 ,

Table 4.1: Demographics of Sample, North Carolina and National

\section{Variable}

Age $(\mathbf{N}=872)$

- 23 - 39 years

- $40-49$ years

- $50-70$ years

Gender ( $N=726)$

- Male

- Female

Place of Work (N = 714)

- Hospital

- Ambulatory Care

- Community Health

- Mental Health

- Nursing Education

- Long-term care

- School nurse

- Other

Patient Population $(\mathrm{N}=\mathbf{6 8 8})$

- ICU /trauma

- Emergency Dept.

- Administration

- Education

- Ambulatory Care

- Medical-surgical floor

- Pediatric floor

- OB-GYN floor

- Oncology

- Other

Patient Acuity Level ( $\mathrm{N}=$ 699)

- $0=$ self-care

- $1=$ minimal assistance

- 2

- 3

- 4 = total care

Highest Degree Earned ( $\mathrm{N}=722$ )

- Diploma

- Associate degree

- BSN

- MSN

- $\quad$ Other Masters

- $\quad \mathrm{PhD}$ (nursing)

- Other Doctoral

\section{Frequency (\%)}

$$
\begin{gathered}
275(32 \%) \\
329(38 \%) \\
265(30 \%) \\
\\
39(5.37 \%) \\
687(94.63 \%) \\
440(61.62 \%) \\
47(6.58 \%) \\
24(3.36 \%) \\
22(3.08 \%) \\
16(2.24 \%) \\
27(3.78 \%) \\
10(1.40 \%) \\
128(17.93 \%)
\end{gathered}
$$

$86(12.50 \%)$

48 (6.98\%)

40 (5.81\%)

32 (4.65\%)

$50(7.27 \%)$

76 (11.05\%)

18 (2.62\%)

50 (7.27\%)

27 (3.92\%)

261 (37.94\%)

77 (11.02\%)

96 (13.73\%)

153 (21.89\%)

253 (36.19\%)

120 (17.17\%)

94 (13.02\%)

281 (38.92\%)

266 (36.84\%)

57 (7.89\%)

19 (2.63\%)

$4(0.55 \%)$

$1(0.14 \%)$
N.C.

National

\begin{tabular}{cc} 
& $31.7 \%$ \\
& $34.4 \%$ \\
& $33 \%$ \\
$7 \%$ & \\
$93 \%$ & $5.4 \%$ \\
& $94.6 \%$ \\
$52.5 \%$ & $59.1 \%$ \\
$*$ & $9.5 \%$ \\
$5.7 \%$ & $12.8 \%$ \\
$1.9 \%$ & $*$ \\
$2 \%$ & $2.1 \%$ \\
$6.4 \%$ & $6.9 \%$ \\
$*$ & $2.6 \%$ \\
$*$ & $*$ \\
& \\
$*$ & $16.9 \%$ \\
$5.6 \%$ & $7.9 \%$ \\
$2.8 \%$ & $5.7 \%$ \\
$3.3 \%$ & $2.8 \%$ \\
$*$ & $*$ \\
\hline
\end{tabular}

$11.7 \%$

$32.4 \%$

$4.4 \%$

$6.8 \%$

$2.7 \%$

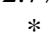

* *

* $*$

$*$

$*$

$13.2 \%$

$40.2 \%$

$30.8 \%$

$7.1 \%$

$2.9 \%$

$0.3 \%$

$0.4 \%$
$6.6 \%$

$8.2 \%$

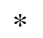

$*$

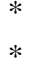

$*$

$*$

$22.3 \%$

$34.3 \%$

$30.7 \%$

$7.5 \%$

$2.0 \%$

$0.3 \%$

$0.3 \%$ 
and 33\% ages 50 years and older (USDHHS, 2002), compared to the sample with percentages of $32 \%$ between the ages of less than 25 years to 39 years, $38 \%$ between the ages of 40 and 49 years, and 30\% between the ages of 50 years to 65 years and over. The sample has a higher percentage of nurses in the 40 to 49 year old age group, making the sample group slightly younger than the national population. Employment settings reported nationally were $59.1 \%$ employed in a hospital setting, $6.9 \%$ in long term care and 2.1\% in nursing education (USDHHS, 2002). In North Carolina, 52.5\% reported employment in an in-patient hospital setting, 6.4\% employed in long term care and 2\% employed in nursing education. In terms of employment for this sample, $61.62 \%$ reported employment in a hospital setting, 3.78\% employed in long term care and 2.24\% in nursing education. While the sample is representative of and relatively reflective of the national and state populations, those individuals in the sample are more likely to work in a hospital setting and less likely to work in long term care. Generally, the sample respondents are reasonably close to state and national demographics. Demographic data related to the sample is summarized in Table 4.1.

\section{Research Question \#1: Results}

Research Question \#1: What are the levels of caring and burnout for registered nurses?

The Caring Behaviors Inventory (CBI) measured the nurses’ perceptions of caring attitudes and actions. The CBI is designed to assess perceptions in five carative categories, but the researcher's factor analysis results of the CBI decreased this to four carative categories by combining two of the original categories. The results of the CBI for this sample indicated that nurses scored high in all four carative categories, meaning 
that the majority perceived all of the attitudes and actions as "caring” in 96\% to 99\% of the sample. The first carative category was respectful deference to others, which includes caring activities such as being honest with the patient, showing respect for the patient and giving the patient information to make decisions (Brunton \& Beaman, 2000). A second carative category was assurance of human presence and attentiveness to others’ experiences. Assurance of human presence includes such caring activities as helping the patient, talking with the patient, appreciating the patient as a human being and responding quickly to the patient’s call (Brunton \& Beaman, 2000). Attentiveness to others' experiences includes activities that relieve the patient's symptoms, put the patient first and just giving good physical care (Brunton \& Beaman, 2000). A third carative category was positive connectedness and includes such activities as being hopeful for the patient, allowing the patient to express feelings and trusting the patient (Brunton \& Beaman, 2000). A fourth, and final, carative category was professional knowledge and skill and includes activities such as watching over the patient, being confident with the patient and paying special attention to the patient on the first visit (Brunton \& Beaman, 2000).

Burnout is separated into three dimensions - emotional exhaustion, personal accomplishment and depersonalization. All questions were measured on a seven-point Likert-type scale anchored by Never (0) and Every Day (6).

Total emotional exhaustion was measured by combining responses to nine questions related to this dimension of burnout. Total emotional exhaustion scores had a possible range of 0 to 54 with a higher score being indicative of a higher level of emotional exhaustion (which leads to a higher level of burnout). The mean for total emotional exhaustion in this sample $(\mathrm{N}=727)$ was 23.04 , compared to a normative mean 
of 20.99. Additionally, 313 (43\%) scored above the mean while the remaining 57\% scored below the mean on this dimension. Therefore, $43 \%$ indicated an increased level of burnout in the area of emotional exhaustion.

\section{Table 4.2}

Means and Standard Deviations for MBI Subscales: Study Sample Compared to Normative Data

$\begin{array}{ccc}\begin{array}{c}\text { Emotional } \\ \text { Exhaustion } \\ (\text { EET })\end{array} & \text { Depersonalization } & \begin{array}{c}\text { Personal } \\ \text { Accomplishment }\end{array} \\ & (\mathrm{DPT}) & (\mathrm{PAT})\end{array}$

\section{Normative data}

$(\mathrm{N}=11,067)$

$\begin{array}{cccc}\text { M } & 20.99 & 8.73 & 34.58 \\ \text { SD } & 10.75 & 5.89 & 7.11\end{array}$

\section{Study sample}

$(\mathrm{N}=773)$

$\mathrm{M}$

SD
23.04

11.70
6.80

6.11
38.66

6.64

t value $4.734^{*}$

$8.51^{*}$

4.08*

7.11

$* \mathrm{p}<.001$

The highest level and incidence of burnout for this sample was noted in the burnout dimension of emotional exhaustion. Table 4.2 compares the means and standard deviation for the scores for this sample to the MBI-HSS normative data (Maslach and Jackson, 1996).

Total depersonalization was measured by combining responses from five questions regarding one's negative or excessively detached response to other people. Total depersonalization scores had a possible range of 0 to 30. The mean for total depersonalization $(\mathrm{N}=727)$ was 6.80 , compared to a normative mean of 8.73 , indicating that the sample has lower levels of burnout than the national norms. Additionally, the 
scores ranged 0 to 30 with 354 (49\%) scoring above the mean and 373 (51\%) scoring below the mean.

Total personal accomplishment was measured by combining responses to eight questions regarding their feeling of job-related competence and successful achievement. Total personal accomplishment scores had a possible range of 0 to 48 . The mean for total personal accomplishment $(\mathrm{N}=722)$ was 38.66, compared to a normative data mean of 34.58. The scores ranged 12 to 48 with 250 (35\%) scoring below the mean. The sample scored higher in the dimension of personal accomplishment than the national data. An increase in personal accomplishment is positive and indicates lower levels of burnout in this sample than in the national data.

\section{Caring Behaviors Inventory: Factor Analysis}

To answer research question \#2 a factor analysis was performed on the Caring Behaviors Inventory, since evidence of construct validity was weak. The Caring Behaviors Inventory (CBI) was used to measure five carative factors - respectful deference to others, assurance of human presence, attentiveness to other's experiences, professional knowledge and skill and positive connectedness. Exploratory factor analysis on this sample was conducted since a factor analysis of the CBI was not reported in the literature to delineate the factor structure of the theory for the CBI used with nurses only and information was not provided on construct validity of the instrument (previous factor analysis was completed using combined nurse and patient responses (Wolf et al., 1994), which are not consistent). The factor analysis provided information on construct validity and the factor structure (Table 4.3). 
Table 4.3

Factor Loadings for Caring Behaviors Inventory Variables

\begin{tabular}{|c|c|c|c|c|}
\hline Variable/Item \# & Factor 1 & Factor 2 & Factor 3 & Factor 4 \\
\hline Respectful deference 1 & 24 & -2 & $39 * *$ & -8 \\
\hline Respectful deference 2 & -10 & 3 & 36 & 12 \\
\hline Respectful deference 3 & 19 & -5 & $38 * *$ & -5 \\
\hline Respectful deference 4 & 23 & 3 & 31 & 1 \\
\hline Respectful deference 6 & 2 & -12 & $51 *$ & 30 \\
\hline Respectful deference 9 & -7 & 8 & $48 *$ & 20 \\
\hline Assurance of presence 5 & 8 & $55^{*}$ & 10 & 6 \\
\hline Assurance of presence 6 & -19 & $53 *$ & 10 & 5 \\
\hline Assurance of presence 9 & 19 & $57 *$ & 0 & 2 \\
\hline Assurance of presence 10 & 11 & $64 *$ & 14 & -15 \\
\hline Knowledge and skill 1 & -2 & -9 & 6 & $75^{*}$ \\
\hline Knowledge and skill 2 & 18 & 1 & -4 & $65^{*}$ \\
\hline Knowledge and skill 3 & -7 & 2 & 22 & $50 *$ \\
\hline Knowledge and skill 4 & -1 & 33 & 5 & $45^{*}$ \\
\hline Knowledge and skill 5 & 5 & 1 & 17 & $52 *$ \\
\hline Attentiveness 1 & -3 & $53 *$ & -9 & 22 \\
\hline Attentiveness 3 & 9 & $52 *$ & -3 & 13 \\
\hline Connectedness 1 & 65* & 0 & 12 & 7 \\
\hline Connectedness 3 & $60 *$ & -5 & 1 & -5 \\
\hline Connectedness 4 & $57 *$ & 6 & 16 & 10 \\
\hline Connectedness 5 & $59 *$ & 12 & 3 & -2 \\
\hline Connectedness 6 & $49 *$ & 5 & 7 & 11 \\
\hline Connectedness 9 & $55 *$ & 14 & -1 & 7 \\
\hline
\end{tabular}

Printed values are multiplied by 100 and rounded to the nearest integer. Values greater than 0.38 are flagged by an '*'.

Factor 1: positive connectedness; Factor 2: assurance of human presence and attentiveness to other's experiences; Factor 3: professional knowledge and skill; Factor 4: respectful deference to others.

Responses to the 43-item questionnaire, measuring five different carative factors were subjected to an exploratory factor analysis using squared multiple correlations as 
prior communality estimates. The principal factor method was used to extract the factors, and this was followed by a promax (oblique) rotation. A scree test (Figure 4.1) suggested four meaningful factors, so only these factors were retained for rotation.

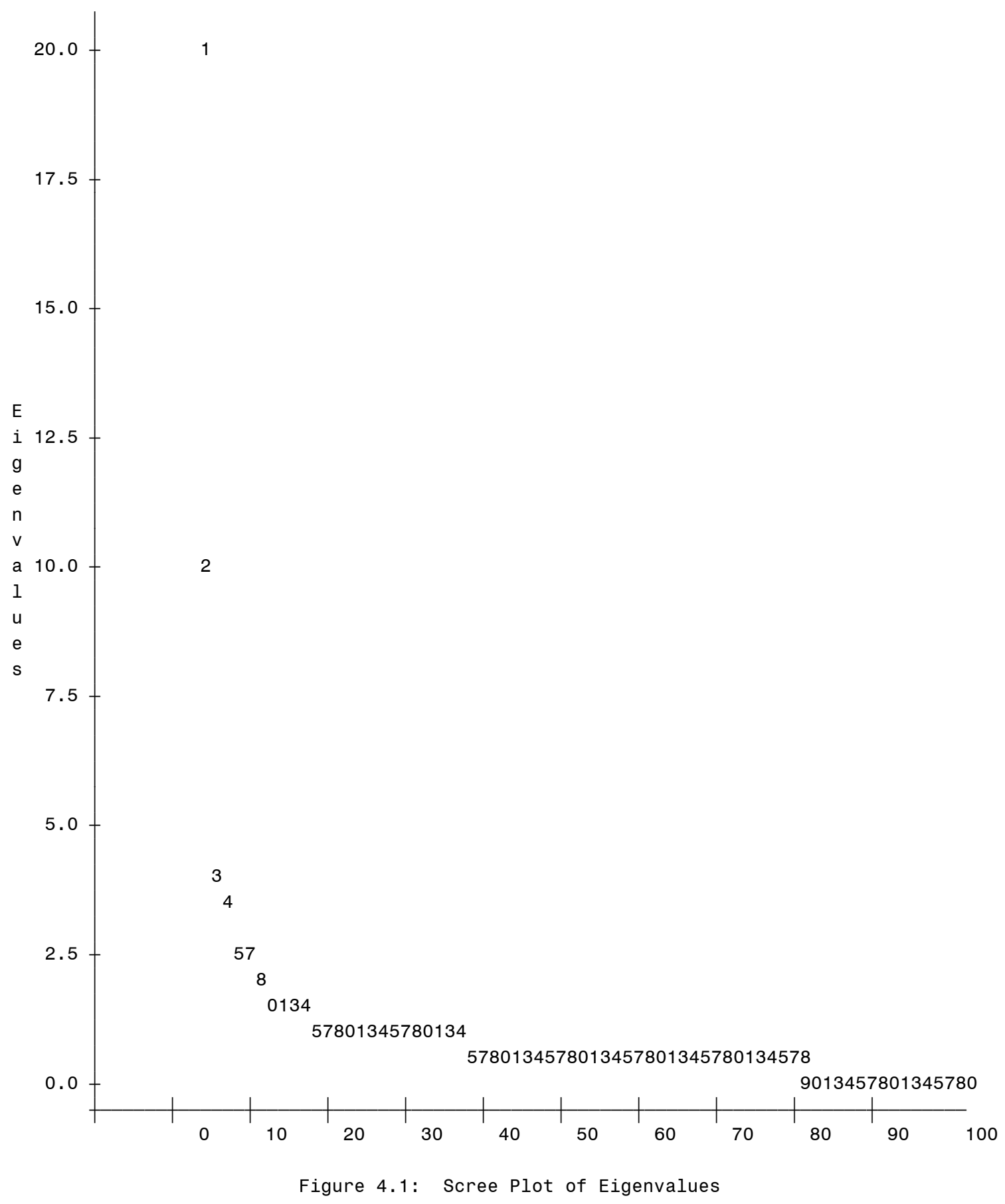


In interpreting the rotated factor pattern, an item was said to load on a given factor if the factor loading was .38 or greater for that factor, and was less than .38 for the other. Using these criteria, six items were found to load on the first factor, which was subsequently labeled positive connectedness. Six items also loaded on the second factor, which was labeled the assurance of human presence and attentiveness to other's experiences. Five items loaded on the third factor, which was labeled professional knowledge and skill. Finally, six items loaded on the fourth factor, which was labeled respectful deference to others. Questionnaire items and corresponding factor loadings are presented in Table 4.3.

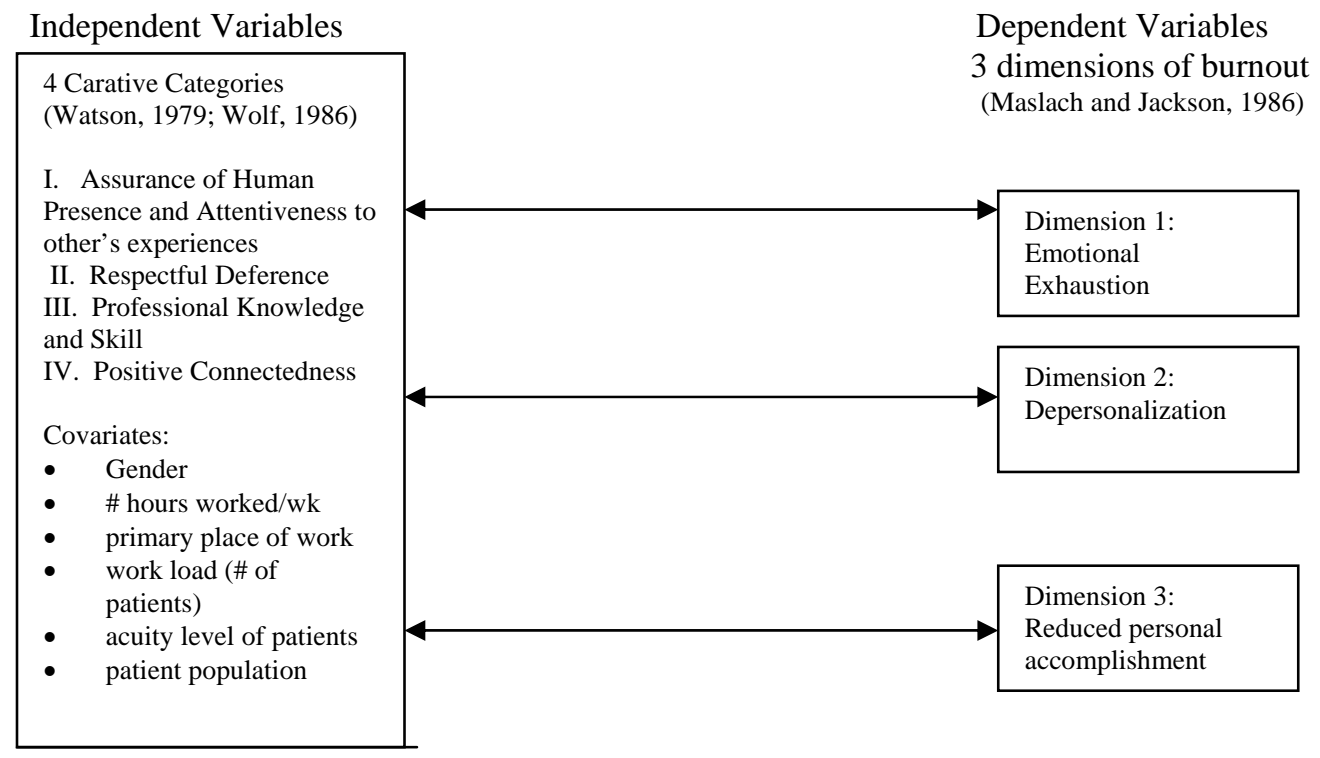

Figure 4.2: Revised Conceptual Framework

Given the results of the exploratory factor analysis, the original conceptual framework noted in Chapter I has been modified as noted in Figure 4.2. The original theoretical structure consisted of five factors, the number of factors that were produced from the factor analysis were four. The original contained five carative categories, but 
after factor analysis contains only four as the original factors I (assurance of human presence) and V (attentiveness to other's experiences) were combined. From this point forward, four carative factors will be referred to, not five.

\section{Research Question \#2: Results}

Research Question \#2: What is the predictive value of the four carative categories (assurance of human presence and attentiveness to other's experiences, respectful deference, professional knowledge and skill, and positive connectedness) on emotional exhaustion, holding constant gender, number of hours worked per week, work load (average number of patients per day), acuity level of patients, primary place of work and patient population?

As previously discussed, the model was changed to include four caring factors, as opposed to the original five, after factor analysis of the CBI revealed that the theoretical factor structure did not hold up with the five factors. A bivariate correlation was completed to determine which of the four carative factors had a significant effect on the emotional exhaustion dimension of burnout. From the bivariate correlations (Table 4.4), two of the four carative factors (assurance of human presence combined with attentiveness to others’ experiences (ASSUPRT) and positive connectedness (POSCONNT)) were significant with emotional exhaustion at $\mathrm{p}<.05$. The two independent variables of respectful deference to the other (RESDEFT) and professional knowledge and skill (PROKNOWT) correlate with the emotional exhaustion dimension of burnout, but not at a statistically significant level of $\mathrm{p}<.05$, and were therefore omitted from the regression model. However, the variable of respectful deference was very close to being statistically significant at $p=.08$. It is therefore important to note that the 
practice of being certain to inform patients to assist them in making healthcare decisions, as well as being honest with them, also compliments the carative factors of assurance combined with attentiveness and professional knowledge and skills and affects the emotional exhaustion associated with burnout.

Table 4.4

Bivariate Correlations

\begin{tabular}{|c|c|c|c|c|c|c|c|}
\hline \multirow{2}{*}{$\mathrm{EET}^{1}$} & $\begin{array}{l}\mathrm{EET}^{1} \\
1.00000\end{array}$ & $\mathrm{DPT}^{2}$ & $\mathrm{PAT}^{3}$ & ASSUPRT $^{4}$ & RESDEFT $^{5}$ & POSCONNT $^{6}$ & PROKNOWT $^{7}$ \\
\hline & 773 & & & & & & \\
\hline \multirow[t]{2}{*}{$\mathrm{DPT}^{2}$} & $\begin{array}{r}0.58153 \\
<.0001\end{array}$ & 1.00000 & & & & & \\
\hline & 773 & 773 & & & & & \\
\hline \multirow[t]{2}{*}{$\mathrm{PAT}^{3}$} & -0.40332 & -0.39532 & 1.00000 & & & & \\
\hline & $\begin{array}{r}<.0001 \\
773\end{array}$ & $\begin{array}{r}<.0001 \\
773\end{array}$ & 773 & & & & \\
\hline \multirow[t]{3}{*}{ ASSUPRT $^{4}$} & -0.07451 & -0.23253 & 0.30217 & 1.00000 & & & \\
\hline & 0.0384 & $<.0001$ & $<.0001$ & & & & \\
\hline & 773 & 773 & 773 & 773 & & & \\
\hline \multirow[t]{3}{*}{ RESDEFT $^{5}$} & -0.06281 & -0.22627 & 0.30543 & 0.62223 & 1.00000 & & \\
\hline & 0.0809 & $<.0001$ & $<.0001$ & $<.0001$ & & & \\
\hline & 773 & 773 & 773 & 773 & 773 & & \\
\hline \multirow[t]{3}{*}{ POSCONNT $^{6}$} & -0.07536 & -0.27804 & 0.31511 & 0.69682 & 0.58970 & 1.00000 & \\
\hline & 0.0367 & $<.0001$ & $<.0001$ & $<.0001$ & $<.0001$ & & \\
\hline & 769 & 769 & 769 & 769 & 769 & 769 & \\
\hline \multirow[t]{3}{*}{ PROKNOWT $^{7}$} & -0.00096 & -0.09664 & 0.12745 & 0.55913 & 0.46676 & 0.48439 & 1.00000 \\
\hline & 0.9788 & 0.0072 & 0.0004 & $<.0001$ & $<.0001$ & $<.0001$ & \\
\hline & 773 & 773 & 773 & 773 & 773 & 773 & 773 \\
\hline
\end{tabular}

1 Emotional exhaustion total; 2 Depersonalization total; 3 Personal accomplishment total; 4 Assurance of human presence and attentiveness to other's experiences total; 5 Respectful deference to other’s total; 6 Positive connectedness total; 7 Professional knowledge and skill total.

NOTE: 1st number is correlation; 2nd number is p-value; 3rd number is $\mathrm{N}$.

Using multiple regression, the emotional exhaustion scores were then regressed on the linear combination of assurance of human presence combined with attentiveness to others' experiences (ASSUPRT) and positive connectedness (POSCONNT), as well as the covariates of gender, hours worked, number of patients, acuity level of patients, place of work and patient population. The equation containing these variables accounted for 
$2 \%$ of the variance in emotional exhaustion dimension of burnout, $F(8,642)=2.57, \mathrm{p}=$ 0.0090 , adjusted $\mathrm{R}^{2}=.02$. While the model is significant at $\mathrm{p}<.05$, neither of the independent variables were statistically significant predictors (Table 4.5).

\section{Table 4.5}

Regression Analyses Predicting Emotional Exhaustion Dimension of Burnout

\begin{tabular}{|c|c|c|c|c|}
\hline $\begin{array}{l}\text { Independent Variable } \\
\text { 1. Assurance of human } \\
\text { presence and } \\
\text { attentiveness to others' } \\
\text { experiences }\end{array}$ & $\begin{array}{c}\boldsymbol{b} \\
-.02\end{array}$ & $\begin{array}{c}\mathbf{B}^{\mathbf{a}} \\
-.003\end{array}$ & $\begin{array}{c}\mathbf{t} \\
-.06\end{array}$ & $\begin{array}{l}\mathbf{p} \\
.95\end{array}$ \\
\hline $\begin{array}{l}\text { 2. Positive } \\
\text { connectedness }\end{array}$ & -.41 & -.10 & -1.88 & .06 \\
\hline 3. Gender & -4.00 & -.08 & $-2.02 *$ & .04 \\
\hline 4. Hours worked & .09 & .06 & 1.46 & .15 \\
\hline 5. Number of patients & .04 & .04 & 1.02 & .31 \\
\hline $\begin{array}{l}\text { 6. Acuity level of } \\
\text { patients }\end{array}$ & 1.19 & .13 & $2.94 *$ & .003 \\
\hline 7. Place of work & .08 & .02 & .42 & .67 \\
\hline 8. Patient population & .04 & .01 & .26 & .80 \\
\hline
\end{tabular}

The results indicate that as the two carative factors of assurance of human presence and attentiveness to others' experiences and positive connectedness increased, burnout in the dimension of emotional exhaustion slightly decreased. For every unit increase in one's assurance of human presence and attentiveness to others' experiences, there was a decrease of .003 in the burnout dimension of emotional exhaustion. For every unit increase in one's positive connectedness, there was a decrease of .10 in the burnout dimension of emotional exhaustion. In other words, there were two carative 
factors that were inversely related to burnout, so that as caring increased, burnout decreased, but not at a level of significant effect.

The p value for positive connectedness is .06, and in the realm of significance, does have an effect. As nurses talk with patients, become more sensitive to the patients' needs and develop a trusting relationship with the patient, the nurse becomes more involved with the patient and their family. One might expect that this building rapport and a relationship might increase a nurse's attachment to a patient and therefore lead to increased levels of burnout, particularly in the dimension of emotional exhaustion. However, this study indicates that the development of a relationship with a patient and their family actually decreases burnout in the dimension of emotional exhaustion. Perhaps this type of caring makes the job more personal and rewarding, increasing job satisfaction, which has been shown to decrease burnout.

Additionally, the covariate of acuity level of patients is statistically significant at $\mathrm{p}=.003$. As one would expect, higher patient acuity levels, those patients in more serious conditions requiring intensive care and monitoring, would increase one’s burnout, particularly in the dimension of emotional exhaustion. This is anticipated as these nurses experience many patient deaths and serious injuries and illnesses. When caring for patients who require this level of care, the time the nurse has to interact with the patient and family and develop a relationship with them (i.e. become more "connected" with them) is greatly diminished and burnout in the dimension of emotional exhaustion is increased. This correlates with the findings previously discussed. 


\section{Research Question \#3: Results}

Research Question \#3: What is the predictive value of the four carative categories (assurance of human presence and attentiveness to other's experiences, respectful deference, professional knowledge and skill, and positive connectedness) on the second dimension of burnout (depersonalization), holding constant gender, number of hours worked per week, work load (average number of patients per day), acuity level of patients, primary place of work and patient population?

As previously discussed, the model was changed to include four caring factors, as opposed to the original five, after factor analysis of the CBI revealed that the theoretical factor structure did not hold up with the five factors. A bivariate correlation was completed to determine which of the four carative factors had a significant effect on the depersonalization (DPT) dimension of burnout. From the bivariate correlations (Table 4.4), all four carative factors were significant at $\mathrm{p}<.05$. Therefore, the depersonalization dimension of burnout correlates with all four of the independent variables $(\mathrm{p}<.05)$ and they were all used in the regression model.

Using multiple regression, the depersonalization scores were then regressed on the linear combination of respectful deference to the other (RESDEFT), assurance of human presence combined with attentiveness to others’ experiences (ASSUPRT), professional knowledge and skill (PROKNOWT) and positive connectedness (POSCONNT), as well as the covariates of gender, hours worked, number of patients, acuity level of patients, place of work and patient population. The equation containing these variables accounted for $11 \%$ of the variance in the depersonalization dimension of burnout, $\mathrm{F}(10,640)=9.11, \mathrm{p}<.0001$, adjusted $\mathrm{R}^{2}=.11$. While the model is significant at 
$\mathrm{p}<.05$, only one of the independent variables, positive connectedness, was a statistically significant predictor (Table 4.6). Assurance of human presence combined with attentiveness to others' experiences $(\mathrm{p}=.24)$ and professional knowledge and skill ( $\mathrm{p}=$ .18) were not statistically significant predictors. Respectful deference for the other ( $\mathrm{p}=$ .06) was approaching statistical significance and had a greater effect. Positive connectedness contributed the greatest variance in the depersonalization dimension of burnout. For every unit increase in positive connectedness, there was a decrease of .22 in the burnout dimension of depersonalization.

Table 4.6

Regression Analyses Predicting Depersonalization Dimension of Burnout

\section{Predictor}

1. Respectful

deference to the other

2. Assurance of human presence and attentiveness to others' experiences

\section{b}

$-.37$

$-.19$

$-.07$

$-1.18$

$\mathbf{B}^{\mathbf{a}}$

$-.09$

$-1.86$

p

.06

.24

3. Positive

$-.22$

$-4.14^{*}$

$<.001 *$

connectedness

4. Professional

.18

.06

1.34

.18

knowledge and skill

5. Gender

.31

.01

.31

.75

6. Hours worked

.002

.003

.07

.95

7. Number of patients

.05

.11

$2.72 *$

$.007 *$

8. Acuity level of

.39

.08

1.92

.06 patients

9. Place of work

.03

.01

.36

.72

10. Patient population

$-.14$

$-.08$

$-1.96 *$

$.0499 *$

${ }^{a}$ Beta weights are standardized multiple regression coefficients

${ }^{b}$ t-test for hypothesis that $\mathrm{b}=0$

$* \mathrm{p}<.05$

Model information: $\mathrm{R}^{2}=.11, \mathrm{~F}(10,640)=9.11, \mathrm{p}<.0001$ 
As nurses develop a trusting relationship with the patient and their family and begin to "connect” with them, the nurses' degree of burnout in the area of depersonalization decreases. As was discussed in the results of research question \#2, this result may seem to be unexpected. However, yet again, this study indicates that a greater connectedness of the nurse to the patient decreases the nurse's degree of burnout. The covariate that was statistically significant, but with a small effect, in predicting burnout in the dimension of depersonalization was the number of patients assigned to the nurse $(\mathrm{p}=$ .007). The covariate of acuity level of patients certainly approaches statistical significance and appears to impact depersonalization at $\mathrm{p}=.06$ As the number of patients assigned to the nurse increased and the acuity level of these patients increased, the degree of burnout in the dimension of depersonalization also increased. The predictive value of this model is modest, to fair, at best in predicting burnout. Of the variables included in the regression model for depersonalization that were significant, the most significant was the caring factor of positive connectedness.

\section{Research Question \#4: Results}

Research Question \#4: What is the predictive value of the four carative categories (assurance of human presence and attentiveness to other's experiences, respectful deference, professional knowledge and skill, and positive connectedness) on the third dimension of burnout (reduced personal accomplishment), holding constant gender, number of hours worked per week work load (average number of patients per day), acuity level of patients, primary place of work and patient population?

As previously discussed, the model was changed to include four caring factors, as opposed to the original five, after factor analysis of the CBI revealed that the theoretical 
factor structure did not hold up with the five factors. A bivariate correlation was completed to determine which of the four carative factors had a significant effect on the personal accomplishment (PAT) dimension of burnout. From the bivariate correlations (Table 4.4), all four carative factors were significant at $\mathrm{p}<.05$. Therefore, the reduced personal accomplishment dimension of burnout correlates with all four of the independent variables $(\mathrm{p}<.05)$ and they were all used in the regression model.

Using multiple regression, the personal accomplishment scores were then regressed on the linear combination of respectful deference to the other (RESDEFT), assurance of human presence combined with attentiveness to others' experiences (ASSUPRT), professional knowledge and skill (PROKNOWT) and positive connectedness (POSCONNT) as well as the covariates of gender, hours worked, number of patients, acuity level of patients, place of work and patient population. The equation containing these variables accounted for $15 \%$ of the variance in the reduced personal accomplishment dimension of burnout, $\mathrm{F}(10,640)=12.48, \mathrm{p}<.0001$, adjusted $\mathrm{R}^{2}=.15$. The model is significant at $\mathrm{p}<.05$ and all four of the carative factors were significant predictors of personal accomplishment (Table 4.7). Respectful deference for the other (p $<.0001$ ), assurance of human presence combined with attentiveness to others’ experiences $(\mathrm{p}=.0130)$, professional knowledge and skill $(\mathrm{p}=.0193)$ and positive connectedness $(\mathrm{p}=.0012)$ were all significant predictors of the personal accomplishment dimension of burnout. Respectful deference for the other contributed the greatest variance in personal accomplishment. For every unit increase in respectful deference, there was an increase of .22 in the personal accomplishment dimension of burnout. For every unit increase in positive connectedness, there was an increase of .17 in the personal 
accomplishment dimension of burnout. For every unit increase in assurance of human presence and attentiveness to others' experiences, there was an increase of .14 in the personal accomplishment dimension of burnout. Finally, for every unit increase in professional knowledge and skill, there was a decrease of .10 in the personal accomplishment dimension of burnout.

Table 4.7

Regression Analyses Predicting Personal Accomplishment Dimension of Burnout

\begin{tabular}{|c|c|c|c|c|}
\hline Predictor & $\boldsymbol{b}$ & $\mathbf{B}^{\mathbf{a}}$ & $\mathbf{t}$ & $\mathbf{p}$ \\
\hline $\begin{array}{l}\text { 1. Respectful deference to } \\
\text { the other }\end{array}$ & .95 & .22 & $4.52 *$ & $<.0001^{*}$ \\
\hline $\begin{array}{l}\text { 2. Assurance of human } \\
\text { presence and attentiveness } \\
\text { to others' experiences }\end{array}$ & .43 & .14 & $2.49 *$ & $.01 *$ \\
\hline 3. Positive connectedness & .40 & .17 & $3.25 *$ & $.001^{*}$ \\
\hline $\begin{array}{l}\text { 4. Professional knowledge } \\
\text { and skill }\end{array}$ & -.34 & -.10 & $-2.34 *$ & $.02 *$ \\
\hline 5. Gender & .76 & .03 & .71 & .48 \\
\hline 6. Hours worked & -.005 & -.006 & -.15 & .88 \\
\hline 7. Number of patients & .01 & .03 & .71 & .48 \\
\hline 8. Acuity level of patients & -.03 & -.005 & -.13 & .89 \\
\hline 9. Place of work & .03 & .01 & .26 & .80 \\
\hline 10. Patient population & .02 & .009 & .23 & .82 \\
\hline
\end{tabular}

As stated in Chapter III, lower mean scores on the personal accomplishment subscale corresponds to higher levels of burnout and higher scores indicate reduced levels of burnout. All four of the carative categories included in the model were statistically significant and all except professional knowledge and skill were predictive for higher scores in personal accomplishment. This indicates that as nurses care more through connecting with patients and developing trusting relationships with patients, they have 
lower levels of burnout in the area of personal accomplishment. Professional knowledge and skill, which one could argue is an expectation and not "caring," resulted in a decrease in the scores, indicating a higher level of burnout. Perhaps the tasks and psychomotor skills do not increase personal fulfillment and satisfaction as connecting with other humans does. In turn, this increase in personal satisfaction leads to an overall lowered level of burnout.

\section{Limitations}

In addition to the fact that it was assumed the respondents answered truthfully, the limitations of this study lie in three major areas. These three areas are the qualitative nature of the concept of caring, the fact that this was a mailed survey, and the Caring Behaviors Inventory. Caring is an often elusive concept and difficult to quantify. Webster defines caring as "to feel interest or concern." Feelings change from day to day, minute to minute based upon situations, personal relationships and work environments. Therefore, to capture a true sense of a nurse's perception of caring in a quantitative measure, a valid and reliable instrument must be developed. The review of the literature for this study revealed a very limited archive of quantitative research on caring, but a multitude of qualitative studies.

A mailed survey was used as more potential subjects could be reached, thereby increasing the possibility of a greater number of responses. However, mailed surveys also have their disadvantages. One major disadvantage of using a mailed survey for this research is that nurses who were experiencing burnout may have been more likely to respond than those who were not experiencing burnout. 
Upon completion of the writing of this study, it was noted that three of the six covariates, which were held constant in each of the regression models, were coded inappropriately to best determine their effect on burnout. These three covariates were gender, primary place of work and patient population. Rather than being effect coded or measured using ordinal scales, these three covariates were measured on nominal scales. Based upon literature review, these covariates have not been as significant in their impact on burnout as the covariates of hours worked, patient acuity level and number of patients. While this oversight in coding would most likely not significantly impact the study results, a change in the coding of these three covariates would be advised should this study be replicated.

The researcher identified the Caring Behaviors Inventory (CBI) as the best available instrument to study caring in a quantitative manner and the one that correlated with the theory of caring (Watson's Theory of Caring) the study was based upon. It was not until the analysis phase of the study that the researcher noted problems with the instrument. One concern is the use of "professional knowledge and skill" as a carative factor. One might ask how does this fit in with the affective concept of caring. Professional knowledge and skill is really skill and not affect. Does a nurse have to have high levels of knowledge and skill to be a caring nurse? Can a nurse be extremely knowledgeable and exhibit great skill in procedures, but not convey a sense of caring?

The greatest limitation to the study in terms of the CBI was that no previous research found by this researcher reported a validity or factor analysis of the instrument when administered to a group of nurses. When a factor analysis was conducted for this sample on the CBI, it was found that all CBI factors had high correlation between factors. 
Using a loading factor of .40 , the results indicated that the theoretical factor structure did not hold up (as discussed in Chapter IV). A significant number of questions did not load in their assigned factor. After running the factor analysis on all CBI factors, four factors emerged from the original five, after deleting nineteen questions. This raises the question as to whether or not the CBI truly measures Watson's Theory of Caring as it was described. The CBI needs further study and revision(s) to effectively measure the theory in samples of nurses. Therefore, there are numerous implications for practice and future research related to the measurement of caring in nursing, which will be discussed in the next chapter. 


\section{Chapter V \\ Discussion}

\section{Summary and Conclusions}

The population studied in this project was all registered nurses (RNs) within the state of North Carolina. The sample was randomly chosen from a listing of all RNs, currently employed full-time in nursing, in North Carolina. The majority of the subjects were female in the age range of 40 to 49 years, were employed in a hospital setting and their highest degree was an associate or baccalaureate degree in nursing.

In terms of level of burnout, measured by the Maslach Burnout Inventory (MBI), the sample had significantly higher levels of burnout in the area of emotional exhaustion and was comparable to the normative data in the areas of depersonalization and personal accomplishment. The highest level of burnout for the study sample was in the area of emotional exhaustion - the dimension of burnout in which the individual has feelings of being emotionally overextended and depleted of their emotional resources - where the sample mean was 23.04 compared to the normative mean of 20.99. The level of burnout for this sample was much less in the dimensions of reduced personal accomplishment and depersonalization. The mean of the study sample in the dimension of reduced personal accomplishment was 38.66, compared to the normative mean of 34.58. A higher score in this particular dimension indicates a decreased level of burnout. Finally, in the dimension of depersonalization, the study sample had a mean of 6.80, compared to the normative mean of 8.73, again, indicating a lower level of burnout in that dimension.

The Caring Behaviors Inventory (CBI) measured the nurses’ perceptions of caring attitudes and actions. As discussed in Chapter IV, the CBI is designed to assess perceptions in five carative categories, but the researcher's factor analysis results of the 
CBI decreased this to four carative categories by combining two of the original categories. The results of the CBI for this sample indicated that nurses scored high in all four carative categories, meaning that the majority perceived all of the attitudes and actions as "caring" in $96 \%$ to $99 \%$ of the sample. The first carative category was respectful deference to others, which includes caring activities such as being honest with the patient, showing respect for the patient and giving the patient information to make decisions (Brunton \& Beaman, 2000). A second carative category was assurance of human presence and attentiveness to others' experiences. Assurance of human presence includes such caring activities as helping the patient, talking with the patient, appreciating the patient as a human being and responding quickly to the patient's call (Brunton \& Beaman, 2000). Attentiveness to others' experiences includes activities that relieve the patient's symptoms, put the patient first and just giving good physical care (Brunton \& Beaman, 2000). A third carative category was positive connectedness and includes such activities as being hopeful for the patient, allowing the patient to express feelings and trusting the patient (Brunton \& Beaman, 2000). A fourth, and final, carative category was professional knowledge and skill and includes activities such as watching over the patient, being confident with the patient and paying special attention to the patient on the first visit (Brunton \& Beaman, 2000).

Finally, the main purpose of this study was to determine the predictive value of the four carative factors on each of the three dimensions of burnout, holding constant gender, number of hours worked per week, work load (average number of patients per day), acuity level of patients, primary place of work and patient population. The four carative categories had the greatest impact on the burnout dimension of personal accomplishment 
as they accounted for $15 \%$ of the variance for personal accomplishment. The carative factor of respectful deference for the other contributed the greatest variance in personal accomplishment with an increase of .22 for every unit increase in respectful deference. The carative factors accounted for only $2 \%$ of the variance in the emotional exhaustion dimension of burnout and $11 \%$ in the depersonalization dimension of burnout (only positive connectedness was a significant predictor). Overall, increases in caring led to decreased burnout for this sample.

\section{Discussion}

If burnout among nurses is to be prevented, it is critical that key causes of burnout be identified and targeted for direct intervention. Aiken et al. (2001) report that $40 \%$ of hospital nurses experience levels of burnout that exceed the norms for health care workers and report job dissatisfaction four times greater than the average for all United States workers. Additionally, one in five hospital nurses indicate that they plan to leave their current nursing positions within a year (Aiken et al., 2001). The literature discusses burnout among nurses, but has primarily focused on burnout due to task-related variables. Yet some evidence indicates that aspects of caring for others, or client-related variables, are just as predictive or more predictive of burnout (Schaufeli and Enzmann, 1998).

Two over-arching problems exist - methodological concerns and lack of research directly linking caring and burnout. First, the concept of caring is one of the least understood ideas used by professionals (Watson, 1979), and remains a poorly defined concept in nursing practice (Kyle, 1995). Caring is considered an elusive and imprecise concept by some (Kyle, 1995). Others view caring as an extremely complex concept, with high levels of caring often attributed to higher burnout rates. The etiology of 
burnout is multifactorial and is determined by complex interactions of occupational and nonoccupational factors and numerous mediators and moderators (Gulielmi and Tatrow, 1998).

\section{Discussion and Conclusion for Research Question One}

The first research question was "what are the levels of caring and burnout for registered nurses?” Burnout was measured using the Maslach Burnout Inventory Human Services Survey (MBI-HSS) with burnout separated into three dimensions emotional exhaustion, depersonalization and personal accomplishment (Maslach and Jackson, 1996).

Level of Burnout - Emotional Exhaustion. Emotional exhaustion is defined by Maslach (1996) as "feelings of being emotionally overextended and exhausted by one’s work.” This study's sample exhibited a significantly $(\mathrm{p}<.001)$ greater degree of burnout in the dimension of emotional exhaustion than that of the normative national data for all helping professions (Maslach, 1996). For this study sample the mean score for total emotional exhaustion was 23.04 (possible range 0-54) (SD 11.70) with 43\% indicating an increased level (score >27) of burnout in this area. The mean MBI-HSS score for emotional exhaustion was 20.99 (SD 10.75). In the breakdown of scores by occupational subgroups, the medicine subgroup, which consists of physicians and nurses, the mean emotional exhaustion score was 22.19 (SD 9.53), still lower than that for this sample (Maslach, 1996).

Chung and Corbett (1998) reported data from nursing staff working with challenging behavior clients in hospital-based units and a community-based unit in the United Kingdom. Their study found higher levels of emotional exhaustion in the nurses 
in the hospital-based units, with a mean emotional exhaustion score of 26.51 (SD 12.53), compared to 12.37 (SD 9.09) in the community-based unit. Chang and Corbett’s (1998) work supports the results of this study in the emotional exhaustion dimension of burnout. The majority (61.62\%) of the current study sample was employed in a hospital and exhibited higher levels of emotional exhaustion than the normative data sample, as did the hospital-based nurses in Chung and Corbett’s (1998) study.

How nurses compare to other health professionals in the burnout dimension of emotional exhaustion varies. Akroyd et al. (2001) examined burnout in a group of radiation therapists and found they experienced higher levels of emotional exhaustion (mean 27.9, SD 13.7) than the norm. Akroyd et al. (2002) also found this to be true in a sample of radiographers, who had an emotional exhaustion mean score of 23.7 (SD 12.3). Gupchup et al. (1998) examined burnout of HMO pharmacists. The mean for that sample in the burnout dimension of emotional exhaustion was 19.42 (SD 11.26), a lower burnout level than the norm and of nurses in the previously mentioned studies.

Emotional exhaustion results in feeling that one’s emotional resources for dealing with patients has been depleted. Perhaps nurses experience higher emotional exhaustion due to the amount of time they spend in direct patient care contact. Nurses, more than any other health care professional, spend more time in direct one-on-one contact with patients and their families and often dealing with emotional extremes within and between patient situations. Additionally, due to longer and more frequent shifts, secondary to the current nursing shortage, nurses have less time for self-care and "down time” between working hours. This leads to physical, as well as emotional, exhaustion. 
Level of Burnout - Depersonalization. Depersonalization is defined by Maslach (1996, p. 4) as “an unfeeling and impersonal response toward recipients of one’s service, care, treatment, or instruction.” This study’s sample exhibited a significantly $(\mathrm{p}<.001)$ lower degree of burnout in the dimension of depersonalization than that of the normative national data for all helping professions (Maslach, 1996). In the burnout dimension of depersonalization, the mean for this sample was 6.80 (possible range 0-30) (SD 6.11) with $15 \%$ of the sample indicating a score indicative of increased burnout in this dimension. The mean MBI-HSS score for depersonalization was 8.73 (SD 5.89). In the breakdown of scores by occupational subgroups, the medicine subgroup (physicians and nurses) had a mean depersonalization score of 7.12 (SD 5.22), higher than that for this sample (Maslach, 1996).

Chung and Corbett (1998), in their data from nursing staff working with challenging behavior clients in hospital-based units and a community-based unit in the United Kingdom, also found lower levels of depersonalization in both groups when compared to the normative data. However, in the nurses in the hospital-based units, there was a mean depersonalization score of 7.12 (SD 7.54), compared to 2.25 (SD 3.82) in the community-based unit. Chang and Corbett's (1998) work supports the results of this study in the depersonalization dimension of burnout. Again, as the majority of the current study sample was employed in a hospital and exhibited lower levels of depersonalization than the normative data sample, so did all of the nurses in Chung and Corbett's (1998) study, but the hospital-based nurses in their study were closer to the results of this study with the community-based nurses scoring much lower. 
How nurses compare to other health professionals in the burnout dimension of depersonalization varies. Akroyd et al. (2001) examined burnout in a group of radiation therapists and found they experienced higher levels of depersonalization (mean 10.6, SD 8.9) than the norm. However, in a sample of radiographers, Akroyd et al. (2002) found lower levels of depersonalization. Their sample had a depersonalization mean score of 7.2 (SD 6.4). Gupchup et al. (1998) examined burnout of HMO pharmacists. The mean for that sample in the burnout dimension of depersonalization was 7.55 (SD 6.21), a lower burnout level than the norm and higher than that of nurses in the previously mentioned studies.

With depersonalization, individuals attempt to distance themselves from they patients and their families by ignoring their unique qualities and avoiding engagement. Individuals find the demands of their work more manageable when they consider the recipients of their care as impersonal objects. Unfortunately, prolonged depersonalization leads to indifference and cynical attitudes (Maslach et al., 2001). While burnout is not considered a progressive, staged process, depersonalization tends to occur as a response to exhaustion. Why is it that the nurses in this sample, as well as other cited studies, experienced lower levels of burnout in the dimension of depersonalization? Perhaps one explanation might be that nurses tend to change jobs or leave nursing while in the emotional exhaustion dimension, prior to becoming cynical. However, this may be argued through personal experiences people have had with nurses who are quite cynical in their work and with their patients. More research is needed to possibly determine the rationale behind this finding of lower levels of depersonalization. 
Level of Burnout - Personal Accomplishment. Personal accomplishment is defined by Maslach (1996) as "feelings of competence and successful achievement in one’s work with people.” This study's sample exhibited a significantly $(\mathrm{p}<.001)$ lower degree of burnout in the dimension of personal accomplishment, or a higher level of personal accomplishment, than that of the normative national data for all helping professions (Maslach, 1996). In the burnout dimension of personal accomplishment, the mean for this sample was 38.66 (possible range 0-48) (SD 6.64) with 14\% of the sample indicating a score indicative of decreased burnout in this dimension. The mean MBI-HSS score for personal accomplishment was 34.58 (SD 7.11). In the breakdown of scores by occupational subgroups, the medicine subgroup (physicians and nurses) had a mean personal accomplishment score of 36.53 (SD 7.34), lower than that for this sample (Maslach, 1996). A higher score on the personal accomplishment dimension of burnout indicates lower levels of burnout.

Chung and Corbett (1998), in their data from nursing staff working with challenging behavior clients in hospital-based units and a community-based unit in the United Kingdom, found varied levels of personal accomplishment in both groups when compared to the normative data. The nurses in the hospital-based units had a mean personal accomplishment score of 33.41 (SD 7.21), compared to 34.81 (SD 12.27) in the community-based unit. The majority of the current study sample was employed in a hospital and exhibited higher levels of personal accomplishment (lower levels of burnout) than the normative data sample, so did the community-based nurses in Chung and Corbett’s (1998) study, but the hospital-based nurses in their study exhibited slightly higher levels of burnout, or reduced levels of personal accomplishment. 
How nurses compare to other health professionals in the burnout dimension of personal accomplishment varies. Akroyd et al. (2001) examined burnout in a group of radiation therapists and found they experienced higher levels of personal accomplishment (mean 42.1, SD 8.6) than the norm. In a sample of radiographers, Akroyd et al. (2002) still found higher levels of personal accomplishment, but not as high as in the group of radiation therapists. Their sample had a personal accomplishment mean score of 36.8 (SD 7.7). Gupchup et al. (1998) examined burnout of HMO pharmacists. The mean for that sample in the burnout dimension of personal accomplishment was 39.66 (SD 5.97), a lower burnout level than the norm and lower than that of nurses in the previously mentioned studies.

Individuals with high levels of personal accomplishment (indicating lower burnout) tend to evaluate their achievements at work in a positive manner and believe they have positive impacts on those they come in contact with. This study indicates that nurses in this sample have higher levels of personal accomplishment. While nurses work in demanding, hi-tech, fast paced and dynamic, rapidly changing environments, they also work with varying degrees of autonomy and have direct contact in interacting with patients and families. These factors may combine to give nurses a feeling of satisfaction regarding their work and the worth of their work to others, leading to an increased feeling of personal accomplishment.

Level of Caring. Caring was measured using the Caring Behaviors Inventory (CBI) (Wolf et al., 1994). As previously discussed, a factor analysis of the instrument resulted in four carative factors - respectful deference to others, assurance of human presence and attentiveness to others' experiences, positive connectedness, and 
professional knowledge and skill. For this study's sample, the CBI results indicated that nurses scored high in all four carative factors, indicating that the majority perceived all of the attitudes and actions as "caring” in 96\% to 99\% of the sample. Past research using the CBI has not provided, to the best of this researcher's knowledge, normative data, nor has this type of data been attempted for this instrument. Additionally, due to the results of the CBI factor analysis performed in this study, previous data using the CBI would be difficult to compare.

However, findings from previous research can be compared in terms of practicing nurses' perceptions of caring, but this is not without difficulty. As caring is inherent to nursing, since nursing is considered an art and a science, one would expect that studies on nurses' perceptions of caring would indicate that nurses do believe caring to be important. While it is not surprising that the research related to caring reviewed for this study shows that nurses view caring as an area of high importance, there is very little, if any, consistency on how to measure caring or what aspects are important. "Caring” has no universal or standard definition, therefore, each study’s definition of “caring” differs. In 2001, there were 21 instruments identified to measure caring in the nursing literature (Watson, 2001). Of these 21 instruments, the majority were designed to be completed by patients and gathered data regarding patients' perceptions of nurse caring and the sample sizes ranged from 18 to 356 with one instrument begin given to 1,452 nurses and nursing students. The reported validity and reliability of most of the instruments consisted of test-retest reliability, content and face validity and Cronbach's alpha. Only three of the 21 reported a factor analysis (Watson, 2001). This overview shows the need for some consistency of terminology across instruments measuring the same concept, as well as the 
need for further testing of the instruments with larger sample sizes. Yet another difficulty in comparing past research to this study is that many of the previous studies have used qualitative methodology to research the concept of caring.

However, past research does, in general terms, appear to hold true to the findings of this study in terms of nurse perceptions of the importance of caring attitudes and behaviors. The carative factor of respectful deference for the other contributed the greatest variance in reduced personal accomplishment, but all carative factors were considered important aspects of practice. As previously described, respectful deference for the other involves the development of a helping-trusting relationship and promotion and acceptance of the expression of positive and negative feelings. Respectful deference includes such caring activities as being honest with the patient, showing respect for the patient and giving the patient information to make decisions (Brunton \& Beamon, 2000).

Dyson’s (1996) qualitative study of nurses' conceptualizations of caring identified nine common themes. These nine themes were: consideration and sensitivity, giving of self, work style, motivation, communication and meeting needs, knowledge and learning, individual approach, general approach, and honesty and sincerity. These findings supported the concept that caring is a combination of what the nurse does and what the nurse is like as a person.

A study by Hegedus (1999) examined providers' and consumers' perspectives of nurses' caring behaviors. The providers placed a greater emphasis on behaviors that were more geared towards the comforting aspects of care by encouraging patients to express and vent their feelings. The consumers valued behaviors that recognized their individual 
perspective as well as that of their family and behaviors that helped them anticipate and prepare for change.

Brunton and Beaman's (2000) study of nurse practitioners' perceptions of their own caring behaviors, the relationship between sociodemographic variables, environmental factors, and nurse practitioner's perceptions of their caring behaviors. The top ten caring behaviors, in rank order, were appreciating the patient as a human being, showing respect for the patient, being sensitive to the patient, talking with the patient, treating patient information confidentially, treating the patient as an individual, encouraging the patient to call with problems, being honest with the patient, and listening attentively to the patient.

Arthur et al. (1999) conducted a study to compare and contrast the responses of a large international sample (11 countries) of nurses with regard to caring, professional self-concept and technological influences. Overall, the findings revealed that the nurses sampled believed in creating a sense of trust and developing a confident relationship between nurses and patients based on truth and respect. The items which solicited the highest means for the total sample were: "Creating a sense of trust”; "A confident relationship between a nurse and a patient is one based on trust, truth and respect”' "Allowing the patient to express feelings"; "Paying attention to the patient when he/she is talking”; and “Listening to the patient” (Arthur et al., 1999).

McCance et al. (1999) compared four theories of caring in the nursing research: Madeleine Leininger's Theory of Culture Care, Jean Watson's Theory of human Caring, Simone Roach's theory of caring and Boykin and Schoenhofer's theory of caring. Their review of the key concepts of these theories found that a commonality is the importance 
of both attitude and knowledge in terms of caring. This was found to hold true in previous research studies as well as this study. Additionally, common expressions of "caring" as perceived by nurses consistently include honesty, sincerity, respect and the development of a trusting relationship with the patient. This study is no exception in these findings.

This study was an attempt to look at the construct of caring from a quantitative view. As previously noted, the Caring Behaviors Inventory (CBI) was the instrument used. While the CBI has been used in previous studies (Kyle, 1995; Wolf et al., 1994; Watson, 2001; Brunton \& Beamon, 2000, Wolf et al., 1998), many more studies need to be done using the instrument to help in further development and refinement of the instrument. Additionally, this will add to the work on validity of the instrument, which is ongoing and assists in looking at the predictive validity of the instrument. As the factor analysis of the CBI indicated, in this study, not all items measured what was intended and revealed four, rather than five, carative categories. However, if one examines the concepts which loaded together, assurance of human presence and attentiveness to others' experiences, it is difficult to differentiate definitively between the two.

"Assurance of human presence" combines the three carative interventions of formation of a humanistic-altruistic system of values, instillation of faith-hope, and cultivation of sensitivity to one's self and to others. The category of "assurance of human presence" includes such caring activities as helping the patient, talking with the patient, appreciating the patient as a human being and responding quickly to the patient's call (Brunton \& Beaman, 2000). 
"Attentiveness to others' experiences" is comprised of the two carative interventions of assistance with the gratification of human needs and allowance for existential-phenomenological forces. Activities included in this category are relieving the patient's symptoms, putting the patient first and giving good physical care (Brunton \& Beaman, 2000).

Philosophically, the two concepts of assurance of human presence and attentiveness to others' experiences are so intertwined and linked that it is difficult to separate them. How can you be attentive without being present, and, if nurses are truly present with a patient, then they are being attentive. The complex, intertwined and multidimensional characteristics of the concept of caring are probably why most research on caring is qualitative.

\section{Discussion and Conclusion for Research Question Two}

Research questions two, three and four for this study were designed to investigate how much of the variance in each of the three dimensions of burnout could possibly be explained by a nurse's level of caring? There is extremely limited empirical evidence on the effect of caring on burnout, especially for nurses. This study, while there were difficulties with the CBI instrument, has identified that the carative factors identified in Watson's theory do impact a nurse's level of burnout. As discussed earlier, the four carative categories had the greatest impact on the burnout dimension of personal accomplishment as they accounted for $16.3 \%$ of the variance for personal accomplishment. The carative factor of respectful deference for the other contributed the greatest variance in reduced personal accomplishment with an increase of .22 for every unit increase in respectful deference. These results were statistically significant $(p<.05)$. 
The regression model for emotional exhaustion regressed the emotional exhaustion scores on the linear combination of assurance of human presence combined with attentiveness to others' experiences (ASSUPRT) and positive connectedness (POSCONNT), as well as the covariates of gender, hours worked, number of patients, acuity level of patients, place of work and patient population. The equation containing these variables accounted for $2 \%$ of the variance in emotional exhaustion dimension of burnout, $\mathrm{F}(8,642)=2.57, \mathrm{p}=0.0090$, adjusted $\mathrm{R}^{2}=.02$. While the model is significant at $\mathrm{p}<.05$, neither of the independent variables were statistically significant predictors (Table 4.5).

Additionally, as there was no past research to which to compare this model, it is difficult to say if the predictors truly account for a meaningful amount of variance. Certainly a variance of only $2 \%$ seems quite small and insignificant, but due to the large sample size, computes as statistically significant. In looking at each of the predictive variables (Table 4.5), it is interesting to note that an increase in the carative factors (ASSUPRT and POSCONNT) led to a decrease in the level of burnout, but not at statistically significant levels. In terms of the covariates, as the number of hours worked, number of patients assigned and acuity level of patients increased, so did the level of burnout in the dimension of emotional exhaustion. This finding coincides with previous research findings. The covariate with the greatest impact on emotional exhaustion was the acuity level of the patients, which was statistically significant at $\mathrm{p}=.003$. As discussed in a previous chapter under limitations, it was noted that upon completion of the writing of this study that three of the six covariates, which were held constant in each of the regression models, were coded inappropriately to best determine their effect on 
burnout. These three covariates were gender, primary place of work and patient

population. Rather than being effect coded or measured using ordinal scales, these three covariates were measured on nominal scales.

The regression model for emotional exhaustion is not a very good model as the predictor variables account for only a very small amount of variance, even though the model itself is statistically significant. For future research, it would be recommended to recode the covariates of gender, primary place of work and patient population using "dummy" or effect coding. While this modification might result in some change, it is not thought that it will make a significant change in the effectiveness of the model itself. Another possibility would be to use a multi-level approach. This is suggested since the other two dependent variables, personal accomplishment and depersonalization correlate strongly with emotional exhaustion. These could be added as independent variables in the model. Perhaps one of the most significant problems with the model is that the independent variables of the carative factors are measuring a very subjective construct $-\mathrm{a}$ human concept that falls in the affective domain and is extremely difficult to measure adequately in a quantitative way. This was found to be true with the Caring Behaviors Inventory used for this study, as was noted earlier, in the fact that a factor analysis was completed and found that the instrument most likely needs to have more work done on it to make a truly valid and reliable instrument to measure caring in nurses.

\section{Discussion and Conclusion for Research Question Three}

The regression model for depersonalization regressed the depersonalization scores on the linear combination of respectful deference to the other (RESDEFT), assurance of 
human presence combined with attentiveness to others' experiences (ASSUPRT), professional knowledge and skill (PROKNOWT) and positive connectedness (POSCONNT), as well as the covariates of gender, hours worked, number of patients, acuity level of patients, place of work and patient population. The equation containing these variables accounted for $11 \%$ of the variance in the depersonalization dimension of burnout, $\mathrm{F}(10,640)=9.11, \mathrm{p}<.0001$, adjusted $\mathrm{R}^{2}=.11$. While the model is significant at $\mathrm{p}<.05$, only one of the independent carative factors variables, positive connectedness, was a statistically significant predictor (Table 4.6). Assurance of human presence combined with attentiveness to others' experiences $(\mathrm{p}=.24)$ and professional knowledge and skill $(\mathrm{p}=.18)$ were not statistically significant predictors. Respectful deference for the other $(\mathrm{p}=.06)$ was approaching statistical significance and had a greater effect. Positive connectedness contributed the greatest variance in the depersonalization dimension of burnout.

It is difficult to say if the predictors truly account for a meaningful amount of variance. However, a variance of $11 \%$ does seem large enough to be meaningful in terms of the predictive value of the model. In looking at each of the predictive variables (Table 4.6), it is interesting to note that an increase in three of the four carative factors included in the model (RESDEFT, ASSUPRT and POSCONNT) resulted in a decrease in the burnout dimension of depersonalization. However, only two of these three (RESDEFT and POSCONNT) were statistically significant or approaching statistical significance. In terms of covariates, the findings of this study coincide with those of previous research. As the number of hours worked, number of patients assigned and acuity level of patients increased, so did the level of burnout in the dimension of depersonalization. The 
covariate with the greatest impact on depersonalization was number of patients, which was statistically significant at $\mathrm{p}=.007$. The acuity level of patients had the next greatest impact on depersonalization and approached statistical significance at $\mathrm{p}=.06$. As previously discussed, it was noted upon completion of the writing of this study that three of the six covariates, which were held constant in each of the regression models, were coded inappropriately to best determine their effect on burnout. These three covariates were gender, primary place of work and patient population. Rather than being effect coded or measured using ordinal scales, these three covariates were measured on nominal scales.

\section{Discussion and Conclusion for Research Question Four}

The regression model for depersonalization is modest to fair, at best as the predictor variables account for a moderate amount of variance, even though the model itself is statistically significant. As with the previous model, for future research, it would be recommended to recode the covariates of gender, primary place of work and patient population using "dummy” or effect coding. While this modification might result in some change, it is not thought that it will make a huge change in the effectiveness of the model itself. Again, perhaps one of the most significant problems with the model is that the independent variables of the carative factors are measuring a very subjective construct - a human concept that falls in the affective domain and is extremely difficult to measure adequately in a quantitative way. This was found to be true with the Caring Behaviors Inventory used for this study, as was noted earlier, in the fact that a factor analysis was completed and found that the instrument most likely needs to have more work done on it to make a truly valid and reliable instrument to measure caring in nurses. A more reliable 
and valid instrument would potentially lend more valid scores and stronger regression models.

The regression model for personal accomplishment regressed the personal accomplishment scores on the linear combination of respectful deference to the other (RESDEFT), assurance of human presence combined with attentiveness to others' experiences (ASSUPRT), professional knowledge and skill (PROKNOWT) and positive connectedness (POSCONNT) as well as the covariates of gender, hours worked, number of patients, acuity level of patients, place of work and patient population. The equation containing these variables accounted for $15 \%$ of the variance in the reduced personal accomplishment dimension of burnout, $\mathrm{F}(10,640)=12.48, \mathrm{p}<.0001$, adjusted $\mathrm{R}^{2}=.15$. The model is significant at $\mathrm{p}<.05$ and all four of the carative factors were significant predictors of personal accomplishment (Table 4.7). Respectful deference for the other (p $<.0001$ ), assurance of human presence combined with attentiveness to others' experiences $(\mathrm{p}=.0130)$, professional knowledge and skill $(\mathrm{p}=.0193)$ and positive connectedness $(\mathrm{p}=.0012)$ were all significant predictors of the personal accomplishment dimension of burnout. Respectful deference for the other contributed the greatest variance in personal accomplishment, followed by positive connectedness, assurance of human presence and attentiveness to others' experiences, and professional knowledge and skill.

Of the three models used in this study, this model accounts for the most variance in a dimension of burnout - a variance of $15 \%$ in personal accomplishment dimension of burnout. As previously mentioned, each of the predictive carative factors variables (Table 4.7) led to an increase in personal accomplishment, which translates as a decrease 
in this dimension of burnout, and each was statistically significant. In terms of the covariates, as the number of hours worked increased and acuity levels of patients increased, personal accomplishment decreased (burnout increased). As the number of patients increased, personal accomplishment increased (burnout decreased). All of the covariates were far from being statistically significant, but, with the exception of number of patients, the results are similar to those of previous research. As previously discussed, that three of the six covariates, which were held constant in each of the regression models, were coded inappropriately to best determine their effect on burnout. These three covariates were gender, primary place of work and patient population. Rather than being effect coded or measured using ordinal scales, these three covariates were measured on nominal scales.

The regression model for personal accomplishment is good to moderate, as the predictor variables account for a sizable amount of variance (15\%), and the model is statistically significant. As with the previous models, for future research, it would be recommended to recode the covariates of gender, primary place of work and patient population using "dummy" or effect coding. While this modification might result in some change, it is not thought that it will make a huge change in the effectiveness of the model itself. This researcher contends that perhaps one of the most significant problems with the model is that the independent variables of the carative factors are measuring a very subjective construct - a human concept that falls in the affective domain and is extremely difficult to measure adequately in a quantitative way. This was found to be true with the Caring Behaviors Inventory used for this study, as was noted earlier, in the fact that a factor analysis was completed and found that the instrument most likely needs 
to have more work done on it to make a truly valid and reliable instrument to measure caring in nurses. A more reliable and valid instrument would potentially lend more valid scores and stronger regression models.

Prior to the study, the researcher hypothesized that as nurses cared more, they would most likely be more stressed and therefore, experience higher levels of burnout. The results of this study did not support that hypothesis. While all of the regression models were only moderately predictive at best, they all indicated that increased levels of caring, in the four categories measured, result in lower levels of burnout in all three dimensions. Perhaps this is due to the fact that nurses are more satisfied with their jobs and experience more personal fulfillment when they are able to take the time to develop relationships with patients and families and become "connected" with them and that this increased satisfaction decreases burnout. This concept certainly deserves a closer look in future research.

Previous research has not focused on the relationship between caring and burnout, but on issues such as the relationship between stress and burnout, or job satisfaction and burnout. Perhaps the reasoning behind this is that caring is a difficulty concept to quantify and therefore, difficult to examine in terms of causal effects. Before more research can be done to examine the relationship between caring and burnout, additional research to identify a more consistent definition and aspects of caring must be completed - a challenge, especially within the nursing profession.

\section{Implications for Practice}

So, what does this mean to practice? A look back at what respectful deference for the other means is necessary. Respectful deference to others includes caring activities 
such as being honest with the patient, showing respect for the patient and giving the patient information to make decisions (Brunton \& Beaman, 2000). What makes these activities more stressful or more likely to increase burnout, particularly in the dimension of reduced personal accomplishment than the activities of the other three carative factors?

The results indicate that after respectful deference, positive connectedness has the second greatest impact on burnout followed by assurance of human presence combined with attentiveness to others' experiences and professional knowledge and skill. As previously discussed, it is questionable if professional knowledge and skill is truly a caring attitude or behavior, or is it the delivery of an expected standard of care? Certainly, if one does not have adequate knowledge and skill, the care given will not meet standards and potentially life-threatening mistakes will be made, which may in turn increase stress and therefore burnout. However, this case would be the exception rather than the rule. Assurance of human presence combined with attentiveness to others’ experiences includes activities such as helping the patient, talking with the patient, responding quickly to the patient's call, relieving the patient's symptoms and giving good physical care. Again, this carative factor includes "giving good physical care” and other activities which correspond with professional knowledge and skill. Aside from that, the other activities involved in assurance of human presence combined with attentiveness to others' experiences are more passive and do not necessarily require the development of a relationship with the patient and therefore, does not involve as much investment of self. The less a nurse has to invest herself in a patient's care, the less likely she is to burnout. On the other hand, positive connectedness and respectful deference to others, involves activities which require nurses to develop relationships with patients and to 
make an investment of themselves with the patient(s). Positive connectedness includes activities such as being hopeful for the patient and putting the patient first, in addition to giving good physical care, and respectful deference to others involves being honest with the patient, showing respect for the patient and giving the patient information to make decisions (Brunton \& Beaman, 2000). This increased involvement with the patient, over and beyond delivering adequate physical care, requires some self-disclosure from the nurse, as well as a greater investment of self and one's emotions. Activities of this type often lead to nurses "taking their work home with them," thus increasing their stress and likelihood of burnout.

The question is, what can we do to help nurses prevent this potential cycle? Perhaps through administering both the CBI and MBI to new nurses, we can help them to identify caring attitudes they may have that may potentially increase their risk of burnout. Just having the knowledge of this potential is the first step in preventing the progression to burnout. Should a number of nurses be identified as “at risk” for burnout based upon their caring attitudes and actions, perhaps a support group, mentors, or other type of intervention to help the nurses deal with their emotional involvement and self-investment in their patients could be provided. If individual nurses, or groups of nurses, can be identified as being predisposed to burnout due to their caring attitudes and behaviors, interventions might be developed and implemented to assist nurses in identifying their predisposing factors to burnout and, in turn, reduce or prevent burnout in the future. This is a very important issue in this time of a nursing shortage and changes in healthcare delivery systems. However, based on the results of this study and past research, at this 
time, there are no recommendations for interventions due to problems with instrumentation and measuring the concept of caring.

Maslach, Schaufeli and Leiter (2001) discussed various intervention strategies that have been proposed in past research. Some of these interventions were reactive, trying to treat burnout after it had occurred, and others were proactive, focusing on how to prevent burnout. It was noted that, while research has found that situational and organizational factors play a bigger role in burnout than do individual factors, most discussions of burnout interventions focus primarily on individual-centered solutions. These interventions include removing the worker from the job, or individual strategies for the worker to either strengthen internal resources or changes for work behaviors. While individual-oriented approaches may help individuals to alleviate the emotional exhaustion dimension of burnout, it does not really influence the other two dimensions of burnout. Additionally, in the workplace, where a person has less control over stressors, individual strategies are relatively ineffective. The authors suggest that the most effective mode of intervention is to combine changes in managerial practice with the individual educational strategies, such as relaxation, time management, assertiveness training and teambuilding.

Kennedy and Barloon (1997) examined ways to manage burnout related to caring for nurses employed in a pediatric intensive care unit. They concluded that interventions for the prevention of burnout in this population requires attention to the feelings of the nurses. Strategies suggested by the authors included ethics rounds involving nurses, implementing a colleague or buddy system, peer support groups, encouraging expression of feelings through fine arts, overnight retreats for nurses to grieve, celebrate and share, 
offering nurses a sabbatical from the pediatric critical care unit as a time for renewal and rotating staff in caring for the child who has been a long-term patient in the unit. These suggestions fall in line with the suggestions of Maslach et al. (2001) to combine work site and individual interventions in efforts to prevent burnout.

Henry and Henry (2004) focus on self-care as an important strategy for preventing burnout. Many nurses enter the profession with a desire to care for others and often neglect to care for themselves, which in turn can result in unhealthy caring behaviors and burnout. The authors adhere to the belief that self-caring contributes to healing and minimizes burnout and compassion fatigue, especially when admiration from patients and others is not forthcoming. It is suggested that nurses engage in self-care by building upon their strengths, including non-clinical strengths, practicing positive intentionality, replacing the three B's (bickering, backbiting and blaming) with the three C's (choosing, caring and collaborating), focusing upon possibilities and not problems and engaging in community and a support system. The strategies offered by this source focus on individual strategies, but neglect workplace strategies. The identifying and combining of strategies in these two areas - individual and workplace - needs further research. Many may ask, “why do we need an quantitative instrument to measure caring?” One reason would be to assist in the identification of individuals at high risk of burnout. If identified, these nurses could engage in appropriate interventions which would hopefully, decrease burnout incidence and increase retention. Additional research with this type of instrument would also provide a database to be used for further research and to support or add to information that may be used to assist in proving the need for increasing funds for nursing to increase retention and ease the nursing shortage. 
The Joint Commission on Accreditation of Healthcare Organizations (JCAHO) (2005) recently reported that the shortage of registered nurses is already having an adverse effect on the health care delivery system in the United States. They reported that $90 \%$ of long term care agencies lack sufficient nurse staffing to meet basic care needs and that there are 126,000 nursing positions currently unfilled in hospitals across the country. These trends in nursing shortage are occurring at a time when the acuity level of patients is increasing and the care is more demanding and complex. Furthermore, it is estimated that by 2020, there will be at least 400,000 fewer nurses than needed available to provide care. The nursing shortage presents a crisis situation and also threatens patient safety. JCAHO (2005) also reported that, as of March 2002, staffing levels were a factor in 24\% of the 1,609 sentinel events (unanticipated events resulting in death, injury or permanent loss of function) reported to the commission. JCAHO's report is aimed at providing strategies for addressing the nursing crisis, with an emphasis on retention of current nurse through reduction of burnout, improving staffing ratios and improving workplace environments. The report also focuses on recruitment of individuals into schools of nursing to complete programs and increase the number of new nurses in the workforce. Additionally, we must look beyond recruitment and retention and also look at the quality and attitudes of the nurses who do stay in nursing. Why do they stay? Also, it is not just nurses being burned out and leaving a job or leaving nursing, but nurses who experience burnout and continue in their jobs but with a "bad attitude". How does this impact patient safety, communication, morale of the unit on which this person works and customer satisfaction? Research in this area may be diverse and offer many opportunities for exploration of complex, multidimensional concepts. 


\section{Implications for Education}

With the nursing shortage, schools of nursing are consistently increasing the number of students they admit with the goal of graduating more students prepared to take the licensing exam and go into practice. However, the nursing shortage is not limited to nurses in clinical settings, as there is also a shortage of nursing faculty. As enrollment increases, faculty numbers are not increasing adequately to accommodate the increased number of students. Therefore, faculty are experiencing increasing workload and potentially burnout.

Schools of nursing must seek to create a caring environment for teaching nursing students how to care, as well as for fostering faculty cohesiveness and cohesiveness between faculty and students. In 1990, the National League for Nursing passed a resolution on nursing education which initiated a curriculum revolution. The resolution called for caring being at the heart of nursing education and enhancing caring practices between faculty and students and faculty and faculty (Beck, 2001; Lee-Hsieh et al., 2005). Putting caring at the core of nursing education must begin with nursing faculty.

The American Association of Colleges of Nursing (1998, p. 8) states that caring “encompasses the nurse's empathy for and connection with the patient, as well as the ability to translate these affective characteristics into compassionate, sensitive, appropriate care.” Teaching and role-modeling caring is a challenge in any nursing curriculum. Fahrenwald et al. (2005) suggest that caring may be best demonstrated by nurses' ability to encompass the five core values of professional nursing in their delivery of care. The five core values essential to baccalaureate education include human dignity, integrity, autonomy, altruism, and social justice (AACN, 1998). This requires that 
faculty and students connect on value-based issues of importance to them and appeals to the moral and character development of students. "Values integration must occur throughout the curriculum and provide the conceptual, moral and practical learning necessary to ensure that the future of nursing workforce is grounded in the concept of caring an actualizes this caring through the application of value-based behavior” (Fahrenwald et al., 2005, p. 51).

Tang et al. (2005) studied students' perceptions of effective and ineffective clinical instructors. Their research suggested that teachers' attitudes toward students, not their professional abilities, were more influential in determining the difference between effective and ineffective teachers. Faculty in clinical teaching roles must develop a close working relationship with students and they have a significant influence on students' feelings of success or failure in clinical practice. Therefore, faculty should strive to improve their attitudes toward students (Tang et al., 2005).

Theis (1988) found that the largest number of unethical teaching behaviors involve violation of respect for students. The concept of caring should not apply only to nursing care, but also in the clinical teaching environment. If faculty display friendly attitudes toward students and try to understand their fears and stresses, perhaps faculty will become more empathetic and allow more room for inadequacies while facilitating learning from mistakes in a positive manner (Tang et al., 2005).

Sarmiento et al. (2004) examined workplace empowerment of nurse educators and how it impacted burnout and job satisfaction. The results suggested that enhancing work empowerment of nurse educators may prevent burnout and increase job satisfaction. From this, a domino effect may occur. As faculty feel more empowered and satisfied 
within their jobs, they may carry out their work with greater joy and enthusiasm. This joy and enthusiasm will carry over in faculty-student relationships, which will convey a sense of caring from faculty to students (Sarmiento et al., 2004).

Additionally, a learning environment for adult learners also enhances empowerment (Bankert and Kozel, 2005). In their work, Bankert and Kozel (2005) described a project in which within a school of nursing for a course designed for adult learners that used an interactive pedagogy encompassing caring relationships, critical reflection and adult learning principles. The course also encouraged students and faculty to engage in genuine partnerships, self-discovery and active engagement. The researchers felt that this transformed teaching-learning environment led to a commitment to learn from the students and fostered connections between students and faculty, thereby enriching the educational experience (Bankert and Kozel, 2005).

A dilemma arises in how to create a paradigm shift to allow for more value-based nursing education that incorporates caring as a core value. Perhaps there needs to be, within nursing education, a paradigm shift to transformative learning as opposed to traditional pedagogical approaches, which would allow more student-teacher connection. Transformative learning involves the transformation of frames of reference, such as points of view, habits of mind, and worldviews, and critical reflection on how we come to know (Mezirow, 2000). Mezirow (2000) believes that learning occurs by elaborating existing frames of reference, learning new frames of reference, transforming points of view, or transforming habits of mind.

Transformative learning is stimulated when "disorienting dilemmas," situations which do not fit one's preconceived notions, occur. These dilemmas are the catalyst for 
critical reflection and the development of new ways to interpret experiences (Mezirow, 2000). The educator is key in the process of transformative learning and can best assist the learners through assisting them to focus on and examine assumptions that underlie their beliefs, feelings and actions, helping them to assess the consequences of their assumptions, assisting them to identify and explore alternative sets of assumptions and testing the validity of these new assumptions in reflective dialog. Through this process, learners may become more reflective and critical while being more open to others' views and being less defensive and more accepting of new ideas (Mezirow, 2000).

Gillespie (2005) discussed the student-teacher connection as "a place of possibility" within nursing education. Students reported that they felt known when the faculty recognized their lives outside of school, recognized their individual learning needs and acknowledged their contribution to patient care (Gillespie, 2005). This type of connection with students requires patience and commitment on the part of the faculty. Positive student-teacher relationships require knowing, trust, respect and mutuality (Gillespie, 2005). Educators must examine their own values and beliefs regarding education and their role as educator, with a focus on moving away from the traditional role of teaching-as-evaluation and move more toward developing their relational competence with students. Gillespie (2005) reported that student-teacher connection enhances the students' professional socialization. Additionally, for students at risk of failing or when failing is inevitable, a connected student-teacher relationship helps to preserve the students' dignity, self-worth and future possibilities (Gillespie, 2005).

Another possibility that may be implemented to improve student-teacher connection and caring is Narrative Pedagogy. This modality may also be utilized with 
distance education, which itself presents a unique challenge for "connecting” with students. Narrative Pedagogy is defined by Diekelmann (2002) as a research-based nursing pedagogy that arises out of the shared lived experiences of students, teachers and clinicians in nursing education. Diekelmann (2002) describes these shared experiences as “The Concernful Practices of Schooling Learning Teaching,” and is providing a new language for contemporary nursing education. Narrative Pedagogy engages students and faculty in collectively interpreting narrative accounts of their experiences in the clinical arena (Ironside et al., 2005). Nurses are expected to know and connect with their patients as a central part of their holistic, individualized nursing care. If faculty do not dialogue with students how can this practice be enhanced or explored? Additionally, in Narrative Pedagogy, there is a shift in teachers' attention to language and the Concernful Practices of Schooling, Learning and Teaching, and away from the traditional critique of impersonal academic writing with a consciously developed writing style that often hides the students' true feelings and meanings (Diekelmann et al., 2005). This encourages faculty to look more at "what" students are saying rather than "how" they are saying it, which makes Narrative Pedagogy a feasible approach for distance education. Faculty development in Narrative Pedagogy may well be needed for this approach to be successful in nursing education.

Perhaps a starting point for further investigation would be that school of nursing faculty could be given the CBI to assess their perceptions of caring. Additionally, the CBI could be given to all students upon their admission to the school to assist in identifying at-risk students and give it again at the end of the program of study. Pre- and post-test analysis of the students could be analyzed. Correlations between faculty and 
student scores might also lend interesting results, particularly when looking at students scores at the end of the program, as we all do learn by example and are influenced by the way others treat us. In other words, if faculty scores indicate they do not care, do students scores reflect the same by the end of the program? If faculty do care, do students who begin with low caring scores increase their caring scores by the end of the program? While caring is often considered an innate characteristic, our life experiences and relationships with others certainly impact whether or not we care.

\section{Future Research}

Prior to additional research being performed on the effect of caring on burnout, more research is needed on caring alone. A focus of this research should be to strive toward a more standard, or universal, definition of caring and identifying a set of common attitudes and behaviors related to nurses’ perceptions of caring.

The area of the predictive value of caring on burnout is wide open for abundant future research. More studies to evaluate the quantitative instruments developed to measure nurses' caring from the nurses' perspective are much needed. As this study discovered, more studies are needed in the use of the CBI, and other instruments, with nurses to determine possible revisions to further refine and improve data on validity and reliability, and to make it truly measure the theoretical structure of Watson's Theory of Caring when studying nurses' perceptions of caring. Secondly, studies using other instruments to measure the concept of caring in the theoretical framework of Watson's theory of caring need to be performed to determine if there is consistency in findings between instruments designed to measure the same theoretical constructs. 
Instrument development is a process and is on-going. Currently, there is no "gold standard" instrument to measure the concept of caring quantitatively. Whereas, the "gold standard” for measuring burnout is the Maslach Burnout Inventory. Additional factor analaysis and any more studies using the CBI to measure nurses' perceptions of caring are needed to further refine the CBI. After the instrument is refined, it could be given to different groups of nurses for further testing. Hospital staff nurses could be asked to complete the instrument in a peer-to-peer recruitment scenario. This approach of not having the "request" for completion of the instrument coming from administration would hopefully relieve the staff nurses of the feelings of it being mandatory. Perhaps one staff nurse per unit could be recruited to recruit other staff on their unit to complete the instrument. Additionally, the same approach could be taken within schools of nursing, so that faculty peers recruit other faculty to complete the instrument. The instrument could also be given at various nursing conventions. Collection of data from nurses only and from a variety of backgrounds would provide much data to assist in further instrument development and refinement.

Another possibility would be that of performing a longitudinal study involving administering the instrument, implementing some type of intervention to improve perceptions of caring (and perhaps other concepts) and then retesting. Outcomes that may then be evaluated could be attrition and retention rates for those nurses. Did the intervention make a difference in nurse retention during this time of critical shortage of nurses?

Yet another issue raised by this research is the question of "what about those who care and do not burn out?” Perhaps a follow-up study of those who scored high on 
caring, but did not experience burnout could be completed to assess what resistance factors or characteristics might prevent burnout in certain individuals or groups.

To expand on this study, one must examine the mediators for burnout. Why does burnout occur? Why does it not occur? Is there a difference in individuals' level of stress or how they cope with stress? This study would be guided by Lazarus and Folkman's (1984) work on stress and having subjects complete a stress appraisal. Specifically, a future study should address the work environment (threatening or nonthreatening), staffing shortages and social support. Additionally, a review of the bivariate correlations from this study (Table 4.4) may provide further insight as there was a higher correlation between the independent variables than between the dependent and independent variables.

The study described in this paper could also be replicated within a health care agency, such as a hospital, after revising the survey to include the 24 items (rather than eight) from the Social Provision Scale (Cutrona \& Russell, 1987) and revising the regression models as suggested previously in this chapter under "Discussion.” Findings could assist in identifying agency factors affecting burnout and identifying individuals at risk for burnout. Once identified, interventions could be developed and implemented to help reduce the risk of burnout and therefore, hopefully, increase nurse retention and morale. However, as previously mentioned, interventions for the individual as well as the work environment must be developed as both influence an individual's potential for burnout.

Finally, further research - quantitative and qualitative - is needed to determine if caring attitudes and perceptions of nurses increase burnout levels. Studies should focus 
on, specifically, which attitudes and which dimensions of burnout so that nurses may be made aware of this risk and interventions might be developed and implemented to prevent further burnout. Additionally, longitudinal assessment would be beneficial, but is also a limitation in that there is typically difficulty in accessing appropriate control groups and the ability to follow a group over a period of time and maintaining a large enough sample size. In the long term, this would help in the retention of nurses in practice, thereby, helping to reduce the current shortage of nurses.

\section{Conclusion}

The concept of burnout, especially in the human services professions, is well researched and includes well-tested, valid methods of measurement. On the other hand, the concept of caring remains elusive. While it is definitely considered an important part of nursing, no one can give a consistent definition of the concept or the attitudes and behaviors it involves. It is therefore difficult to determine a causal effect between caring and burnout. This study did identify a causal effect between the four carative factors of the CBI and each dimension of burnout, the effect was relatively low. The greatest effect was that of respectful deference on the burnout dimension of reduced personal accomplishment.

Additional research is needed to verify the results of this study as well as to determine additional causative factors of burnout related to caring. The field of research is open for many studies in this area and are needed to identify causal relationships between caring and burnout and to develop individual and workplace interventions to prevent, or at least reduce, burnout. Hopefully, a reduction in burnout of nurses will aid in the retention of nurses, which will, in turn, assist in lessening the nursing shortage. 


\section{References}

Aiken, L. H., Clarke, S. P., Sloane, D. M. et al. (2001). Nurses' reports on hospital care in five countries. Health Affairs, 20 (1), 43-53.

Akroyd, D. \& Adams, R. D. (2000). The cost of caring: A national study of burnout in radiation therapists. Radiation Therapist, 9 (2), 123-130.

Akroyd, D., Caison, A. and Adams, R. (2002). Patterns of burnout among U.S. radiographers. Radiologic Technology, 73 (3), 215-223.

American Association of Colleges of Nursing. (1998). The Essentials of Baccalaureate Education for Professional Nursing Practice. Washington, D.C.: AACN.

Arthur, D. et al. (1999). Caring attributes, professional self concept and technological influences in a sample of registered nurses in eleven countries. International Journal of Nursing Studies, 36 , 387-396.

Bankert, E. G. \& Kozel, V. V. (2005). Transforming pedagogy in nursing education: A caring learning environment for adult students. Nursing Education Perspectives, 26 (4), 227-229.

Barker, P. (2000). Reflections on caring as a virtue ethic within an evidence-based culture. International Journal of Nursing Studies, 37 (4), 329-336.

Beck, C. T. (2001). Caring within nursing education: a metasynthesis. Journal of Nursing Education, 40 (3), 101-109.

Bevis, E. O. \& Watson, J. (2000). Toward a Caring Curriculum: A New Pedagogy for Nursing. Sudbury, Massachusetts: Jones and Bartlett Publishers.

Boykin, A. \& Schoenhofer, S. (1993). Nursing as Caring: A model for transforming practice. New York: National League for Nursing Press.

Brunton, B. \& Beaman, M. (2000). Nurse practitioners' perceptions of their caring behaviors. Journal of the American Academy of Nurse Practitioners, 12 (11), 451-456.

Chung, M. C. \& Corbett, J. (1998). The burnout of nursing staff working with challenging behavior clients in hospital-based bungalows and a community unit. International Journal of Nursing Studies, 35, 56-64.

Coogan, R. S. (1996). Caring behaviors of perioperative nurses. Unpublished master's thesis, Florida Atlantic University, Boca Raton. 
Cordes, C. L., Dougherty, T. W. \& Blum, M. (1997). Patterns of burnout among managers and professionals: a comparison of models. Journal of Organizational Behavior, 18, 685-701.

Creswell, J.W. (1994). Research Design: Qualitative \& quantitative approaches. Thousand Oaks: Sage Publications.

Cutrona, C. \& Russell, D. (1987). The provisions of social relationships and adaptations to stress. Advances in personal relationships, p. 37-67. Greenwich, CT: JAI Press.

Dames, K. A. (1983). Relationship of burnout to personality and demographic traits in nurses. Dissertation Abstracts International, 44, 1588B.

Diekelmann, N. (2002). Schooling, learning and teaching: Toward a Narrative Pedagogy. Diekelmann Web. http://www.son.wisc.edu/diekelmann/research/slt/index.html. Accessed May 2, 2006.

Diekelmann, N. \& Mendias, E. P. (2005). Being a supportive presence in online courses: Knowing and connecting with students through writing. Journal of Nursing Education, 44 (8), 344-346.

Dillon, R. S. \& Stines, P. W. (1996). A phenomenological study of faculty student caring interactions. Journal of Nursing Education, 35 (3), 113-118.

Dyson, J. (1996). Nurses’ conceptualizations of caring attitudes and behaviors. Journal of Advanced Nursing, 23, 1263-1269.

Fahrenwald, N. L., Bassett, S. D., Tschetter, L., Carson, P. P., White, L., Winterboer, V. J. (2005). Teaching core nursing values. Journal of Professional Nursing, 21 (1), 46-51.

Gillespie, M. (2005). Student-teacher connection: a place of possibility. Journal of Advanced Nursing, 52 (2), 211-219.

Gray-Toft, P. \& Anderson, J. G. (1981). Stress among hospital nursing staff: Its causes and effects. Social Science \& Medicine, 15, 639-647.

Gulielmi, R. S. \& Tatrow, K. (1998). Occupational stress, burnout, and health in teachers: A methodological and theoretical analysis. Review of Educational Research, 68 (1), 61-99.

Gupchup, G. V., Singhal, P. K., Dole, E. J. \& Lively, B. T. (1998). Burnout in a sample of HMO pharmacists using the Maslach Burnout Inventory. Journal of Managed Care Pharmacy, 4 (5), 495-503. 
Hanson, L. E. \& Smith, M. J. (1996). Nursing students’ perspectives:

Experiences of caring and not-so-caring interactions with faculty. Journal of Nursing Education, 35 (3), 105-112.

Hatcher, L. \& Stepanski, E. J. (1999). A Step-by-step Approach to using the SAS System for Univariate and Multivariate Statistics. Cary, N.C.: SAS Institute, Inc.

Hegedus, K. S. (1999). Providers' and consumers' perspective of nurses' caring behaviors. Journal of Advanced Nursing, 30, 1090-1096.

Hobfoll, S. E. (1988). The Ecology of Stress. Washington, D. C.: Hemisphere.

Ironside, P., Diekelmann, N., and Hirschmann, M. (2005). Learning the practices of knowing and connecting: The voices of students. Journal of Nursing Education, 44 (4), 153-155.

Joint Commission on Accreditation of Healthcare Organizations. (2005). Health Care at the Crossroads: Strategies for addressing the evolving nursing crisis. Washington, DC: Joint Commission on Accreditation of Healthcare Organizations.

Kennedy, D. \& Barloon, L. F. (1997). Managing burnout in pediatric critical care: The human care commitment. Critical Care Nursing Quarterly, 20 (2), 63-74.

Kim, H. S. \& Kollak, I. (1999). Nursing Theories: Conceptual and philosophical foundations. New York: Springer Publishing Company.

Kosowski, M. M. R. (1995). Clinical learning experiences and professional nurse caring: A critical phenomenological study of female baccalaureate nursing students. Journal of Nursing Education, 34 (5), 235-242.

Kyle, T. V. (1995). The concept of caring: a review of the literature. Journal of Advanced Nursing, 21, 506-514.

Lazarus, R. S., \& Folkman, S. (1984). Stress, Appraisal, and Coping. New York: Springer.

Lee-Hsieh, J., Kuo, C. L. and Tseng, H. F. (2005). Application and evaluation of a caring code in clinical nursing education. Journal of Nursing Education, 44 (4), 177-184.

Leiter, M. P. (1988). Burnout as a function of communication patterns: A study of a multidisciplinary mental health team. Group and Organization Studies, 13, 111128. 
Leiter, M. P., Harvie, P. \& Frizzell, C. (1998). The correspondence of patient satisfaction and nurse burnout. Social Science \& Medicine, 47 (10), 1611-1617.

Marini, B. (May 1999). Institutionalized older adults’ perceptions of nurse caring behaviors: A pilot study. Journal of Gerontological Nursing, 11-16.

Maslach, C. (1982). Burnout: The Cost of Caring. Englewood Cliffs, NJ: PrenticeHall.

Maslach, C. and Jackson, S. E. (1986). Maslach Burnout Inventory. 2nd ed. Palo Alto, Calif: consulting Psychological Press.

Maslach, C. and Jackson, S. E. (1996). Maslach Burnout Inventory Manual. $3^{\text {rd }}$ ed. Palo Alto, Calif.: Consulting Psychological Press.

Maslach, C., Schaufeli, W. B. \& Leiter, M. P. (2001). Job burnout. Annual Review of Psychology (Annual 2001), 397-419.

McCance, T.V., McKenna, H. P. \& Boore, J. R. P. (1999). Caring: theoretical perspectives of relevance to nursing. Journal of Advanced Nursing, 30 (6), 13881395.

McConnell, E. A. (1982). Burnout in the Nursing Profession: Coping strategies, causes, and costs. St. Louis: C.V. Mosby Company.

Mezirow, J. (2000). Learning as transformation: critical perspectives on a theory in progress. San Francisco: Jossey-Bass.

Melchior, M. E. W., VanDenBerg, A. A., Halfens, R. et al. (1997). Burnout and the work-environment of nurses in psychiatric long-stay settings. Social Psychiatry and Psychiatric Epidemiology, 32, 158-164.

Miller, K. I., Stiff, J. B. \& Ellis, B. H. (1988). Communication and empathy as precursors to burnout among human service workers. Communication Monographs, 55, 250-265.

Moffett, B. S. (2002). Caring as a mediator of burnout in nurses [Abstract]. The Proceedings of the $16^{\text {th }}$ Annual Conference of the Southern Nursing Research Society, San Antonio, Texas, 318.

Oermann, M. H. (1991). Professional Nursing Practice: A conceptual approach. Philadelphia: J.B. Lippincott Company.

Omdahl, B. L. \& O’Donnell, C. (1999). Emotional contagion, empathic concern and communicative responsiveness as variables affecting nurses' stress and occupational commitment. Journal of Advanced Nursing, 29 (6), 1351-1359. 
Patistea, E. \& Siamanta, H. (1999). A literature review of patients' compared with nurses’ perceptions of caring: Implications for practice and research. Journal of Professional Nursing, 15, 302-312.

Sarmiento, T. P., Laschinger, H. K. S. and Iwasiw, C. (2004). Nurse educators' workplace empowerment, burnout, and job satisfaction: testing Kanter's theory. Journal of Advanced Nursing, 46 (2), 135-143.

Sarros, J. C. \& Friesen, D. (1987). The etiology of administrator burnout. Alberta Journal of Educational Research, 33, 163-179.

SAS Institute. (1999-2001). The SAS System: Version8.7. Cary, North Carolina: SAS Institute.

Schaufeli, W. \& Enzmann, D. (1998). The Burnout Companion to Study \& Practice: A critical analysis. Philadelphia: Taylor \& Francis Inc.

Schaufeli, W. B., Maslach, C. \& Marek, T. (1993). Professional Burnout: Recent developments in theory and research. Washington, D. C.: Taylor \& Francis.

Simmons, P. R. \& Cavanaugh, S. H. (2000). Relationships among student and Graduate caring ability and professional school climate. Journal of Professional Nursing, 16 (2), 76-83.

Simonson, C. L. S. (1996). Teaching caring to nursing students. Journal of Nursing Education, 35 (3), 100-104.

Spratley, E., Johnson, A., Sochalski, J., Fritz, M. \& Spencer, W. (2002). The Registered Nurse Population: March 2000: Findings from the National Sample Survey of Registered Nurses. National Center for Health Workforce Analysis. Washington, D.C.: U.S. Department of Health and Human Services Health Resources and Service Administration.

Swan, B. A. (1998). Postoperative nursing care contributions to symptom distress and functional status after ambulatory surgery. MedSurg Nursing, 7, 148-151, 154158.

Tabachnick, B. G. \& Fidell, L. S. (1989). Using Multivariate Statistics. $2^{\text {nd }}$ ed. New York, NY: Harper Collins Publishers, Inc.

Tang, F., Chou, S. and Chiang, H. (2005). Students' perceptions of effective and ineffective clinical instructors. Journal of Nursing Education, 44 (4), 187-192.

Theis, E. C. (1988). Nursing students’ perspectives of unethical teaching behaviors. Journal of Nursing Education, 27, 102-106. 
Um, M. Y. \& Harrison, D. F. (1998). Role stressors, burnout, mediators, and job satisfaction: A stress-strain-outcome model and an empirical test. Social Work Research, 22 (2), 100-115.

Urden, L. D. (1996). Nursing division assessment of organizational management, productivity and quality indicators. Grand Rapids, MI: Butterworth Hosptial.

Walsh, M. \& Dolan, B. (1999). Emergency nurses and their perceptions of caring. Emergency Nurse, 7 (4), 24-31.

Watson, J. (1979). The Philosophy and Science of Caring. Boston: Little, Brown and Company.

Watson, J. (2001). Monograph of Instruments for Assessing and Measuring Caring. New York: Springer Publishing.

Watson, R., Deary, I. J. \& Lea, A. (1999). A longitudinal study into the perceptions of caring among student nurses using multivariate analysis of the Caring Dimensions Inventory. Journal of Advanced Nursing, 30, 1080-1089.

Wolf, Z. R. (1986). The caring concept and nurse identified caring behaviors. Topics in Clinical Nursing, 8 (2), 84-93.

Wolf, Z. R., Colahan, M., Costello, A., Warwick, F., Ambrose, M. S., \& Giardino, E. R. (1998). Relationship between nurse caring and patient satisfaction. MedSurg Nursing, 7 (2), 99-105.

Wolf, Z. R., Giardino, E. R., Osborne, P. A., \& Ambrose, M. S. (1994). Dimensions of nurse caring. IMAGE: Journal of Nursing Scholarship, 26 (2), 107-111. 
$\underline{\text { Appendix A }}$

Cover letter and Survey 
October 2, 2002

Dear Registered Nurse:

My name is Annette Peery, and I am a registered nurse employed full-time in nursing in North Carolina. I am also currently working on my doctorate in Adult Education, Education for the Health Professions, at North Carolina State University. This letter and the enclosed survey are my data collection for my dissertation.

The title of my dissertation is Caring and Burnout in Registered Nurses: What's the Connection? The purpose of this study is to examine how caring directly affects burnout. If individual nurses can be identified as being predisposed to burnout due to their caring attitudes and behaviors, interventions might be developed and implemented to assist nurses in identifying their predisposing factors to burnout and, in turn, reduce or prevent burnout in the future. This is a very important issue in this time of a nursing shortage and changes in healthcare delivery.

Participation in this study involves completing and returning a survey. The purpose of the survey is to evaluate how registered nurses view caring attitudes and actions in their job and job environment.

There are no known risks associated with participation in this study, and no compensation will be provided to participants. The information in the study records, while linked to your name via a code number, will be kept strictly confidential. Data will be stored securely and will be made available only to persons conducting the study unless you specifically give permission in writing to do otherwise. No reference will be made in oral or written reports which could link you to the study.

The enclosed survey will take approximately 20 minutes to complete and all responses will remain confidential. Please complete the enclosed survey and return in the enclosed preaddressed, postage paid envelope by Monday, November 25, 2002. Your consent to participate in this study will be implied by your return of the completed survey.

Again, all responses will be kept confidential. Should you have any questions or concerns, please feel free to contact me via phone at 252-328-4116 or 252-321-8319, or e-mail peerya@mail.ecu.edu. If you feel you have not been treated according to the descriptions in this form, or your rights as a participant in research have been violated during the course of this project, you may contact Dr. Matthew Zingraff, Chair of the NCSU IRB for the Use of Human Subjects in Research Committee, Box 7514, NCSU Campus (919-513-1834) or Mr. Matthew Ronning, Assistant Vice Chancellor, Research Administration, Box 7514, NCSU Campus (919513-2148). Thank you in advance for your participation.

Sincerely,

Annette I. Peery, MSN, RN, CDE

Duane Akroyd, Ph.D. Associate Professor

Adult and Community College

Education

North Carolina State University 


\section{Dissertation Research Survey of Registered Nurses}

The purpose of this survey is to discover how registered nurses view their jobs and the people with whom they work closely. In addition, it will examine how registered nurses view caring attitudes and actions. There are four (4) parts to the survey with 89 items total.

\section{$\underline{\text { PART } 1}$}

The first 22 items are statements of job-related feelings. Please read each statement carefully and decide if you ever feel this way about your job. If you have never had this feeling, write a " 0 " in both the "HOW OFTEN" column before the statement. If you have had this feeling, indicate how often you feel it by writing the number (from 1 to 6) that best describes how frequently you feel that way.

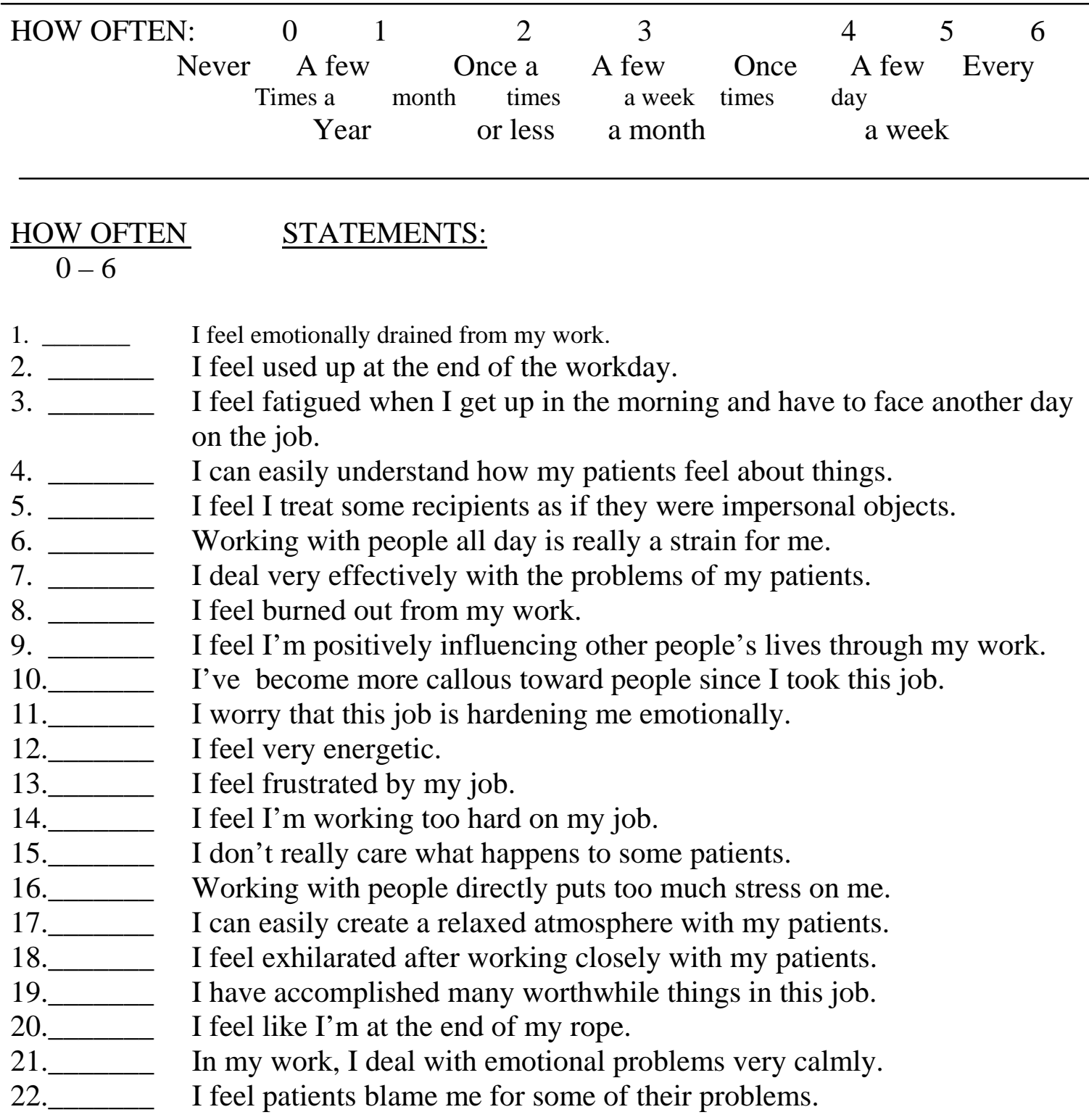




\section{PART 2}

Part 2 contains 43 items. Each item is a statement that relates to a caring attitude or action. For each item, please rate how you view it in relation to its importance to caring on a scale of 1 to 4 .

\begin{tabular}{cccc}
\hline 1 & 2 & 3 & 4 \\
strongly & disagree & agree & $\begin{array}{c}\text { strongly } \\
\text { agree } \\
\text { (not important) }\end{array}$ \\
& & & (very important) \\
\hline
\end{tabular}

\begin{tabular}{|c|c|}
\hline 23. & Attentively listening to patient \\
\hline 24. & Giving instructions or patient teaching \\
\hline 25 & Treating patient as an individual \\
\hline 26. & Spending time with patient \\
\hline 27. & Touching patient to communicate caring \\
\hline 28. & Being hopeful for patient \\
\hline 29. & Giving patient information so that he/she can make a decision \\
\hline 30. & Showing respect for patient \\
\hline 31. & Supporting patient \\
\hline 32. & Calling patient by his/her preferred name \\
\hline 33. & Being honest with patient \\
\hline 34. _ & Trusting patient \\
\hline 35. & Being empathetic or identifying with patient \\
\hline 36. & Helping patient grow \\
\hline 37. & Making patient physically or emotionally comfortable \\
\hline 38. & Being sensitive to patient \\
\hline 39. & Being patient or tireless with patient \\
\hline 40. & Helping patient \\
\hline 41. & Promoting independence of patient \\
\hline 42. & Knowing how to give shots, IV's etc. \\
\hline 43. & Being confident with patient \\
\hline 44. & Using soft, gentle voice with patient \\
\hline 45. & Demonstrating professional knowledge and skill \\
\hline 46. & Watching over patient \\
\hline 47. & Making equipment skillfully \\
\hline 48. & Being cheerful with patient \\
\hline 49. _ & Allowing patient to express feelings about his/her disease and treatment \\
\hline 50. & Including patient in planning his/her care \\
\hline 51. _ & Treating patient information confidentially \\
\hline 52. & Providing reassuring presence \\
\hline 53. & Returning to patient voluntarily \\
\hline 54. & Talking with patient \\
\hline 55. & Encouraging patient to call if there are problems \\
\hline 56. & Meeting patients' stated and unstated needs \\
\hline 57. & Responding quickly to patient’s call \\
\hline
\end{tabular}


58.

Appreciating patient as human being

59. __ Helping to reduce patient's pain

$60 . \quad$ Showing concern for patient

61. Giving patient's treatments and medications on time

62. __ Paying special attention to patient during first times (such as hospitalization and/or treatment)

63. ___ Relieving patient's symptoms

64.__ Putting patient first

65.__ Giving good physical care

\section{PART 3}

Please answer the following questions about your job and yourself.

66. Age (in years)

67. Gender (circle one): male female

68. Are you currently working as a registered nurse?(circle one) yes

no

69. If you are currently working in nursing, as you (circle one) full time

part time

70. On the average, how many hours to you work per week? Hours

71. Which one of the following best describes your place of primary work?

$\square$
$\square$
ambulatory care
community health
mental health
nursing education
long term care
school nurse
OTHER (please specify)

72. Using the following categories, how would you best describe your patient population and/or job activities?

intensive care / trauma unit emergency department administration education ambulatory care medical-surgical floor pediatric floor OB-GYN floor oncology other (please specify) 
73. How would you rate the average acuity level of the patients you work with on a daily basis? (circle one)

$\begin{array}{ccccc}0 & 1 & 2 & 3 & 4 \\ \text { self-care } & \begin{array}{c}\text { minimal } \\ \text { assistance }\end{array} & & & \text { total care }\end{array}$

74. What is the average number of patients you work with during one day?

75. On the average, how many minutes do you spend with each patient in one day?

76. What is the usual shift length that you work?

8 hour 12 hour

77. Do you work days, evenings, nights, or rotate shifts?

78. How many days in a row do you usually work?

79. How many years have you actively practiced as a nurse?

80. Highest degree earned:

Diploma

Associate degree

BSN

MSN

Other Masters

$\mathrm{PhD}$ (nursing)

EdD

Other doctoral degree

81. How many dependent children live in your home?

\section{PART 4}

Part 4 consists of 8 items. The items are about current relationships with friends, family, coworkers, supervisors, and departmental or organizational leaders. For each item, please rate your agreement with the statement on a scale of 1 to 4 .

$$
\begin{aligned}
& 1=\text { strongly disagree } \\
& 2=\text { disagree } \\
& 3=\text { agree } \\
& 4=\text { strongly agree }
\end{aligned}
$$

82. __ There are people I can depend on to help me if I really need it.

83. __ There is no one I can turn to for guidance in times of stress.

84. __ I feel part of a group of people who share my attitudes and beliefs.

85. __ I do not think other people respect my skills or abilities. 
86. If If something went wrong, no one would come to my assistance.

87. _ _ I have relationships where my competence and skill are recognized.

88. _ There is no one I can depend on for aid if I really need it.

89. __ No one needs me to care for them. 